\title{
The Efficiency and Usability Human-Computer Interface in Cervical Spinal Cord Injury by Game-based Electromyography Biofeedback and Electromyography Biofeedback
}

\author{
Mehdi Omidi $^{1}$ (D), Amin Asgharzadeh ${ }^{2}$ (D), Seifollah Gharib ${ }^{3}$ (D), Mohsen Vahedi ${ }^{4}$, \\ Amir Salar Jafarpisheh ${ }^{*}$
}

1. MSc, Department of Ergonomics, University of Social Welfare and Rehabilitation Sciences, Tehran, Iran

2. PhD Student, Department of Biomedical Engineering, University of Shahid Beheshti, Tehran, Iran

3. Assistant Professor, Department of Occupational Health Engineering, Mashhad University of Medical Sciences, Mashhad, Iran

4. Assistant Professor, Department of Biostatistics, University of Social Welfare and Rehabilitation Sciences, Tehran, Iran

5. Assistant Professor, Department of Ergonomics, University of Social Welfare and Rehabilitation Sciences, Tehran, Iran

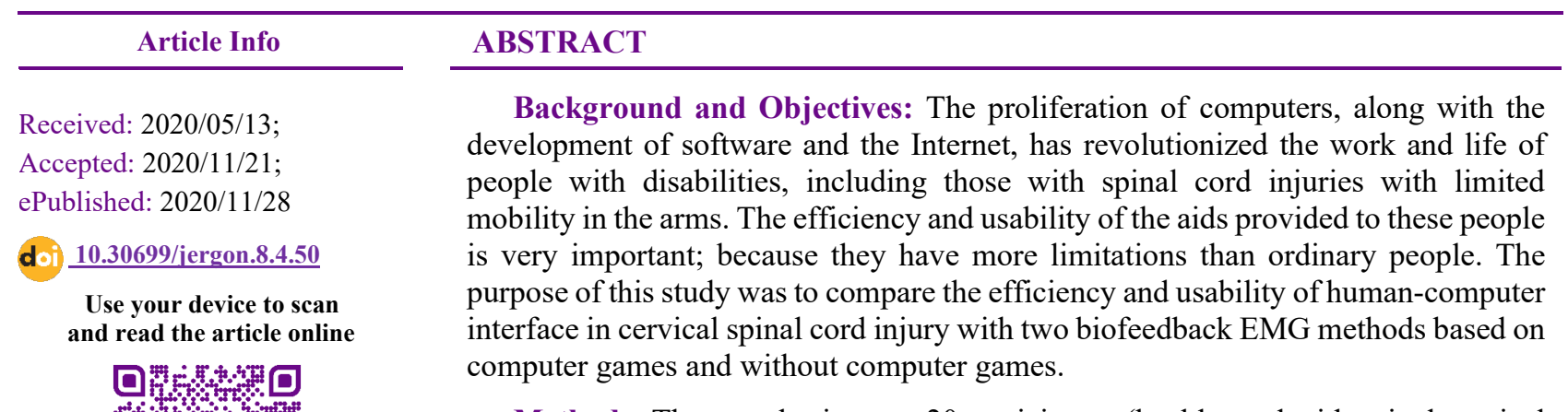

Methods: The sample size was 20 participants (healthy and with spinal cervical lesions) who were selected regarding availability. The statistical population of the study (that was conducted 2019-2020) was spinal cord injury patients referred to spinal cord injury clinic in Tehran. Participants received three 30-minute sessions per week for 1 month of EMG biofeedback training and game-based biofeedback interventions. SPSS version 23 was used for data analysis.

Results: Results showed that participants considered using EMG biofeedback and game biofeedback as $75 / 8 \%$ and $72 / 0 \%$ usability. Over time, the "through put" numerical values of the variable decreased in healthy individuals and spinal cord injury. Also, the numerical values of this variable were lower in healthy individuals than in individuals with spinal cord injuries. The maximum reduction in numerical values of the "through put" variable appeared between the first and sixth sessions.

Conclusion: The EMG and gaming biofeedback system can be used for interaction and control such as computers, wheelchairs, and more.

Keywords: Human-computer interaction, EMG game-based biofeedback, Mouse control, Cervical spinal cord injury

Copyright (C) 2021, This is an original open-access article distributed under the terms of the Creative Commons Attribution-noncommercial 4.0 International License which permits copy and redistribute of the material just in noncommercial usages with proper citation.

\section{How to Cite This Article:}

Omidi M, Asgharzadeh A, Gharib S, Vahedi M, Jafarpisheh A. The Efficiency and Usability Human-Computer Interface in Cervical Spinal Cord Injury by Game-based Electromyography Biofeedback and Electromyography Biofeedback. Iran J Ergon. 2020; 8 (4) :50-68 


\section{Extended Abstract}

\section{Introduction}

The proliferation of computers, along with the development of software and the Internet, has revolutionized the work and life of people with disabilities, including those with spinal cord injuries with limited mobility in the arms. The efficiency and usability of the aids provided to these people is very important; because they have more limitations than ordinary people. The purpose of this study was to compare the efficiency and usability of human-computer interface in cervical spinal cord injury with two biofeedback EMG methods based on computer games and without computer games.

\section{Methods}

The sample size was 20 participants (healthy and with spinal cervical lesions) who were selected regarding availability. The statistical population of the study (that was conducted 2019-2020) was spinal cord injury patients referred to spinal cord injury clinic in Tehran. Participants received three 30-minute sessions per week for 1 month of EMG biofeedback training and game-based biofeedback interventions. SPSS software version 23 (SPSS Inc., Chicago, Ill., USA) was used to analyze the data. Statistical indicators such as mean, standard deviation and statistical tests of mean comparison, Shapiro-Wilk, Tukey and repeated measures were used to describe the data.

Table 1. Participating groups of EMG biofeedback and game species biofeedback

\begin{tabular}{|cc|}
\hline Group 1 & Patient with EMG biofeedback \\
\hline Group 2 & Patient with playful biofeedback \\
\hline Group 3 & Healthy with EMG biofeedback \\
\hline Group 4 & Healthy with playful biofeedback \\
\hline
\end{tabular}

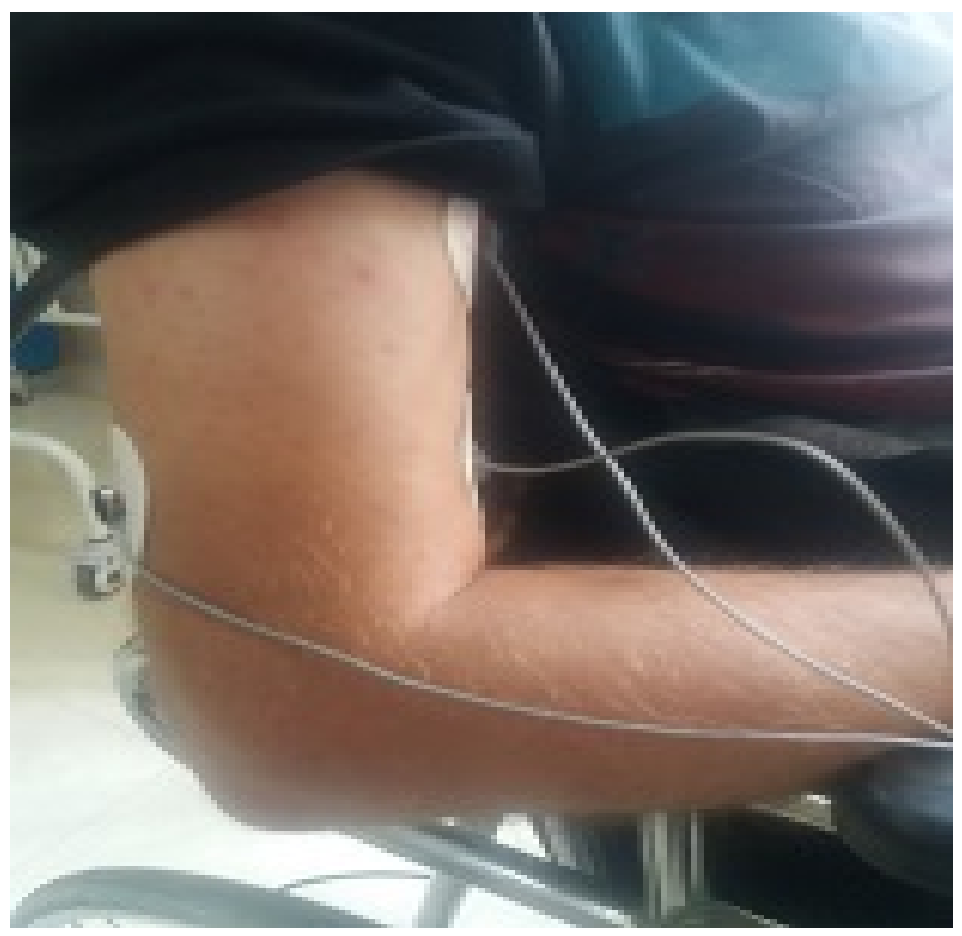

Figure 1. Location of electrodes on participants' biceps 


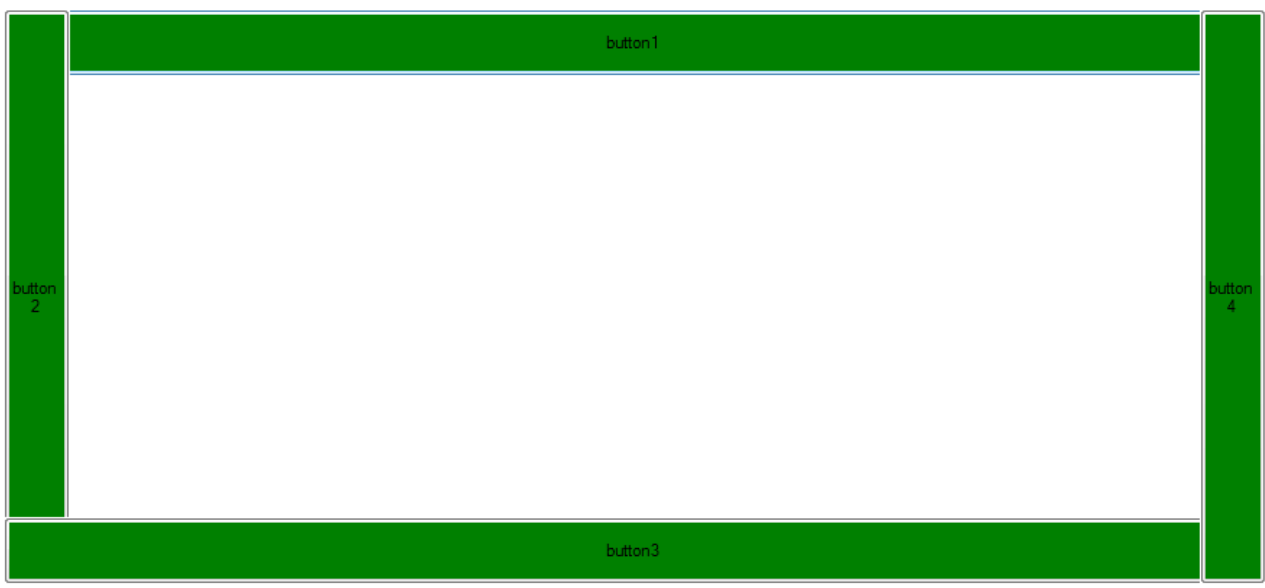

Figure 2. EMG biofeedback image (participants had to move the computer cursor in this green border).

task number:23 $W=100 \quad D=225$

200.767784119749
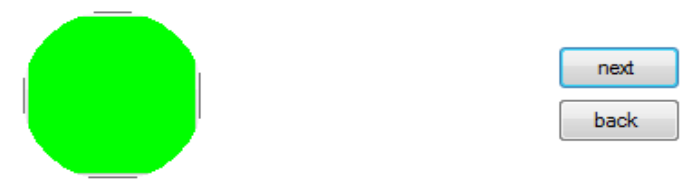

Figure 3. Test screen (participants had to move the computer cursor to the green circles and click).

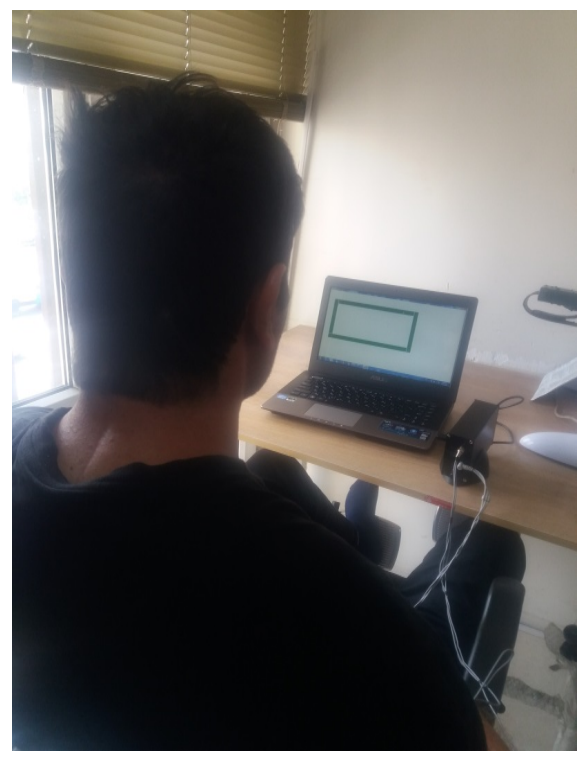

\section{Results}

Results showed that participants considered using EMG biofeedback and game biofeedback as $75 / 8 \%$ and $72 / 0 \%$ usability. Over time, the "through put" numerical values of the variable decreased in healthy individuals and spinal cord injury. Also, the numerical values of this variable were lower in healthy individuals than in individuals with spinal cord injuries. The maximum reduction in numerical values of the "through put" variable appeared between the first and sixth sessions.

Figure 4. Working with EMG biofeedback 
Table 2. Significant comparison between 4 groups participating in the SUS questionnaire

\begin{tabular}{|c|c|c|c|}
\hline & & Mean difference & P-value \\
\hline \multirow{3}{*}{$\begin{array}{c}\text { Patient with EMG } \\
\text { biofeedback }\end{array}$} & $\begin{array}{l}\text { Patient with playful } \\
\text { biofeedback }\end{array}$ & *11.000 & 0.028 \\
\hline & $\begin{array}{c}\text { Healthy with EMG } \\
\text { biofeedback }\end{array}$ & $1.000-$ & 0.991 \\
\hline & $\begin{array}{l}\text { Healthy with playful } \\
\text { biofeedback }\end{array}$ & 7.200 & 0.207 \\
\hline \multirow{3}{*}{$\begin{array}{l}\text { Patient with playful } \\
\text { biofeedback }\end{array}$} & $\begin{array}{l}\text { Patient with EMG } \\
\text { biofeedback }\end{array}$ & $* 11.000$ & 0.028 \\
\hline & $\begin{array}{l}\text { Healthy with EMG } \\
\text { biofeedback }\end{array}$ & $* 10.000$ & 0.049 \\
\hline & $\begin{array}{c}\text { Healthy with playful } \\
\text { biofeedback }\end{array}$ & 3.800 & 0.701 \\
\hline \multirow{3}{*}{$\begin{array}{c}\text { Healthy with EMG } \\
\text { biofeedback }\end{array}$} & $\begin{array}{l}\text { Patient with EMG } \\
\text { biofeedback }\end{array}$ & 1.000 & 0.991 \\
\hline & $\begin{array}{l}\text { Patient with playful } \\
\text { biofeedback }\end{array}$ & *10.000 & 0.049 \\
\hline & $\begin{array}{c}\text { Healthy with playful } \\
\text { biofeedback }\end{array}$ & $6.200-$ & 0.319 \\
\hline \multirow{3}{*}{$\begin{array}{c}\text { Healthy with playful } \\
\text { biofeedback }\end{array}$} & $\begin{array}{c}\text { Patient with EMG } \\
\text { biofeedback }\end{array}$ & 7.200 & 0.207 \\
\hline & $\begin{array}{l}\text { Patient with playful } \\
\text { biofeedback }\end{array}$ & $3.800-$ & 0.701 \\
\hline & $\begin{array}{c}\text { Healthy with EMG } \\
\text { biofeedback }\end{array}$ & 6.200 & 0.319 \\
\hline
\end{tabular}

Table 3. Analysis of variance with repeated measurements of the first session, the sixth session and the twelfth session of the TP variable in 4 groups of participants

\begin{tabular}{|c|c|c|c|c|c|c|c|c|}
\hline $\begin{array}{l}\text { Source of } \\
\text { changes }\end{array}$ & & $\begin{array}{c}\text { Total } \\
\text { squares }\end{array}$ & $\begin{array}{l}\text { Degree } \\
\text { of } \\
\text { freedo } \\
\text { m }\end{array}$ & $\begin{array}{l}\text { Average } \\
\text { squares }\end{array}$ & $\mathbf{F}$ & $\begin{array}{c}\text { Probabilit } \\
\text { y value }\end{array}$ & $\begin{array}{c}\text { Eta } \\
\text { squared }\end{array}$ & $\begin{array}{c}\text { Power of a } \\
\text { test }\end{array}$ \\
\hline \multicolumn{9}{|l|}{$\begin{array}{l}\text { Inside the } \\
\text { subjects }\end{array}$} \\
\hline & Time & 641832.433 & 1.353 & $\begin{array}{c}474293.57 \\
0\end{array}$ & $\begin{array}{c}32.15 \\
8\end{array}$ & 0.000 & 0.668 & 1.000 \\
\hline & $\begin{array}{l}\text { Time and } \\
\text { group }\end{array}$ & 212041.967 & 4.060 & 52230.736 & 3.541 & 0.022 & 0.399 & 0.783 \\
\hline & Error & 319335.600 & 21.652 & 14748.673 & & & & \\
\hline \multicolumn{9}{|c|}{ Between subjects } \\
\hline & Group & $\begin{array}{c}2875586.58 \\
3\end{array}$ & 3 & $\begin{array}{c}958528.86 \\
1\end{array}$ & 6.897 & 0.003 & 0.564 & 0.935 \\
\hline & Error & $\begin{array}{c}2223557.60 \\
0\end{array}$ & 16 & $\begin{array}{c}138972.35 \\
0\end{array}$ & & & & \\
\hline
\end{tabular}


Table 4. Test of Shapiro-Wilk test Normality of Throughput variable

\begin{tabular}{ccccc|}
\hline Group & Test & $\begin{array}{c}\text { Participants of } \\
\text { each group }\end{array}$ & $\begin{array}{c}\text { Probability value } \\
\text { Through put }\end{array}$ \\
(before) & 1 & 0.854 & 5 & 0.208 \\
& 3 & 0.940 & 5 & 0.664 \\
& 4 & 0.987 & 5 & 0.968 \\
Through put & 1 & 0.878 & 5 & 0.299 \\
(while) & 2 & 0.803 & 5 & 0.086 \\
& 3 & 0.917 & 5 & 0.514 \\
& 4 & 0.962 & 5 & 0.825 \\
Through put & 1 & 0.876 & 5 & 0.292 \\
(after) & 2 & 0.654 & 5 & 0.003 \\
\hline
\end{tabular}

Table 5. In-group comparison of throughput variables

\begin{tabular}{|c|c|c|c|}
\hline & Group & Mean difference & P-value \\
\hline \multirow{3}{*}{$\begin{array}{l}\text { Patient with EMG } \\
\text { biofeedback }\end{array}$} & $\begin{array}{l}\text { Patient with playful } \\
\text { biofeedback }\end{array}$ & 339.07 & 0.100 \\
\hline & $\begin{array}{c}\text { Healthy with EMG } \\
\text { biofeedback }\end{array}$ & *507.93 & 0.009 \\
\hline & $\begin{array}{l}\text { Healthy with playful } \\
\text { biofeedback }\end{array}$ & $* 560.13$ & 0.004 \\
\hline \multirow{3}{*}{$\begin{array}{c}\text { Patient with playful } \\
\text { biofeedback }\end{array}$} & $\begin{array}{l}\text { Patient with EMG } \\
\text { biofeedback }\end{array}$ & 339.07- & 0.100 \\
\hline & $\begin{array}{c}\text { Healthy with EMG } \\
\text { biofeedback }\end{array}$ & 168.87 & 0.611 \\
\hline & $\begin{array}{c}\text { Healthy with playful } \\
\text { biofeedback }\end{array}$ & 221.07 & 0.394 \\
\hline \multirow{3}{*}{$\begin{array}{c}\text { Healthy with EMG } \\
\text { biofeedback }\end{array}$} & $\begin{array}{l}\text { Patient with EMG } \\
\text { biofeedback }\end{array}$ & *507.93 & 0.009 \\
\hline & $\begin{array}{l}\text { Patient with playful } \\
\text { biofeedback }\end{array}$ & $168.87-$ & 0.611 \\
\hline & $\begin{array}{c}\text { Healthy with playful } \\
\text { biofeedback }\end{array}$ & 52.20 & 0.980 \\
\hline \multirow{3}{*}{$\begin{array}{c}\text { Healthy with playful } \\
\text { biofeedback }\end{array}$} & $\begin{array}{l}\text { Patient with EMG } \\
\text { biofeedback }\end{array}$ & $* 560.13$ & 0.004 \\
\hline & $\begin{array}{l}\text { Patient with playful } \\
\text { biofeedback }\end{array}$ & $221.07-$ & 0.394 \\
\hline & $\begin{array}{l}\text { Healthy with EMG } \\
\text { biofeedback }\end{array}$ & $52.20-$ & 0.980 \\
\hline
\end{tabular}


Mehdi Omidi et al.,

Table 6. Mean and standard deviation of the Through put variable in 4 groups of participants

Variable

Group

M (bits/s)

SD (bits/s)

First session Patient with EMG biofeedback

Patient with playful biofeedback

Healthy with EMG biofeedback

Healthy with playful biofeedback

Total

4 groups

Patient with EMG biofeedback

Patient with playful biofeedback

Sixth session

Healthy with EMG biofeedback

Healthy with playful biofeedback

4 groups

Total

Patient with EMG biofeedback

Patient with playful biofeedback

Healthy with EMG biofeedback

Healthy with playful biofeedback

session

Total

4 groups
644.40

395.122

401.503

283.908

88.724

107.962

371.00

597.05

386.166

357.80

64.550

262.20

56.082

184.00

57.654

440.859

95.290

46.797

44.755

283.129

258.954

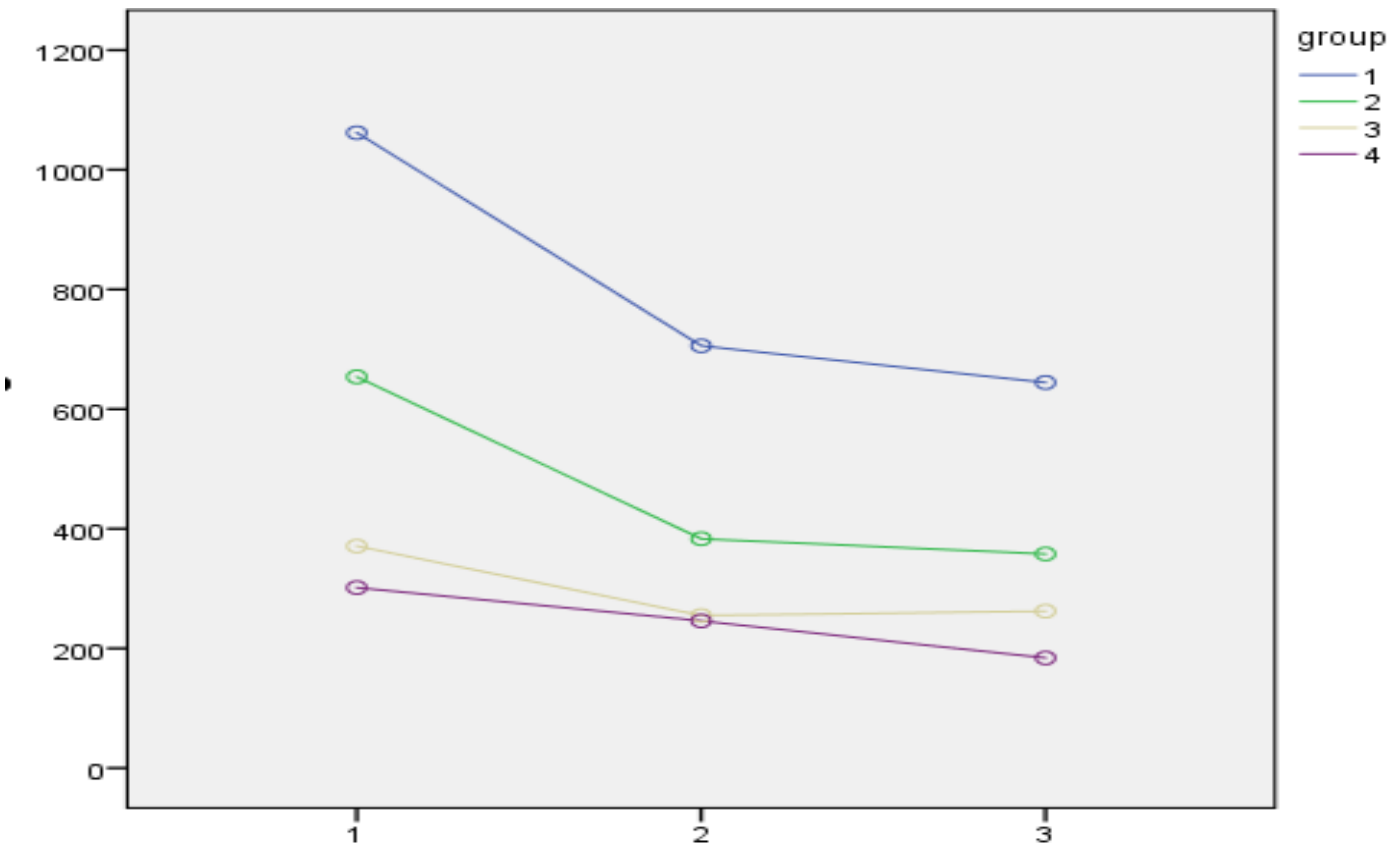

Figure 5. Comparison of the mean of the Through put variable in the first, sixth and twelfth sessions of 4 participating groups 


\section{Discussion}

The maximum slope of change between the first and sixth sessions was created in healthy participants with SCI. This indicates the greatest motor training and learning to use EMG biofeedback with and without games to control the computer marker in the first six sessions of the study. Considering the numerical mean of the variable Through put, it can be said that the amount of changes between the sixth to twelfth sessions was significantly less compared with the sessions between the first and sixth. It can be said that due to poor motor control of patients with spinal cord injuries, the rate of displacement of computer markers was higher than healthy participants; therefore, it can be said that patients with spinal cord injury have gained maximum control and function using playful EMG biofeedback. It is recommended to use playful EMG biofeedback to improve accuracy and muscle control in patients with spinal cord injury. The results of this study are in line with the results of the study of Williams et al. and Lu et al.

\section{Conclusion}

The EMG and gaming biofeedback system can be used for interaction and control such as computers, wheelchairs, and more.

\section{Acknowledgement}

The authors of this article would like to thank all the participants. Also, all the ethical codes provided by the University of Social Welfare and Rehabilitation Sciences in accordance with the code IR.USWR.REC.1397.044 were observed in this research.

\section{Conflict of Interest}

The authors declared no conflict of interest. 
كارايى و كاربرديذيرى واسط انسانرايانه در افراد داراى ضايعةٌ نخاعى گردنى در دو روش بيوفيدبك EMG مبتنى بر بازى رايانهاى و بدون بازى رايانهاى

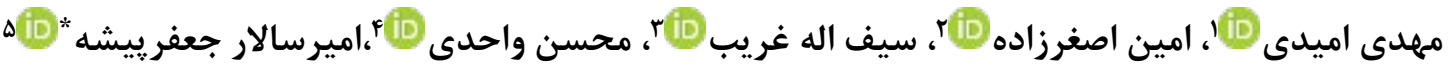

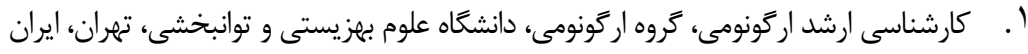

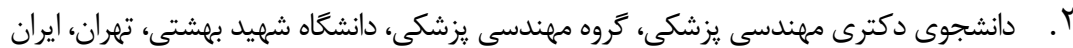

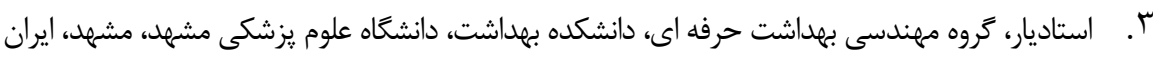

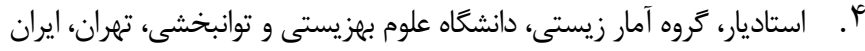

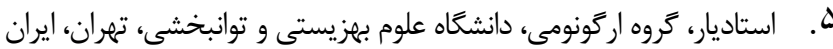

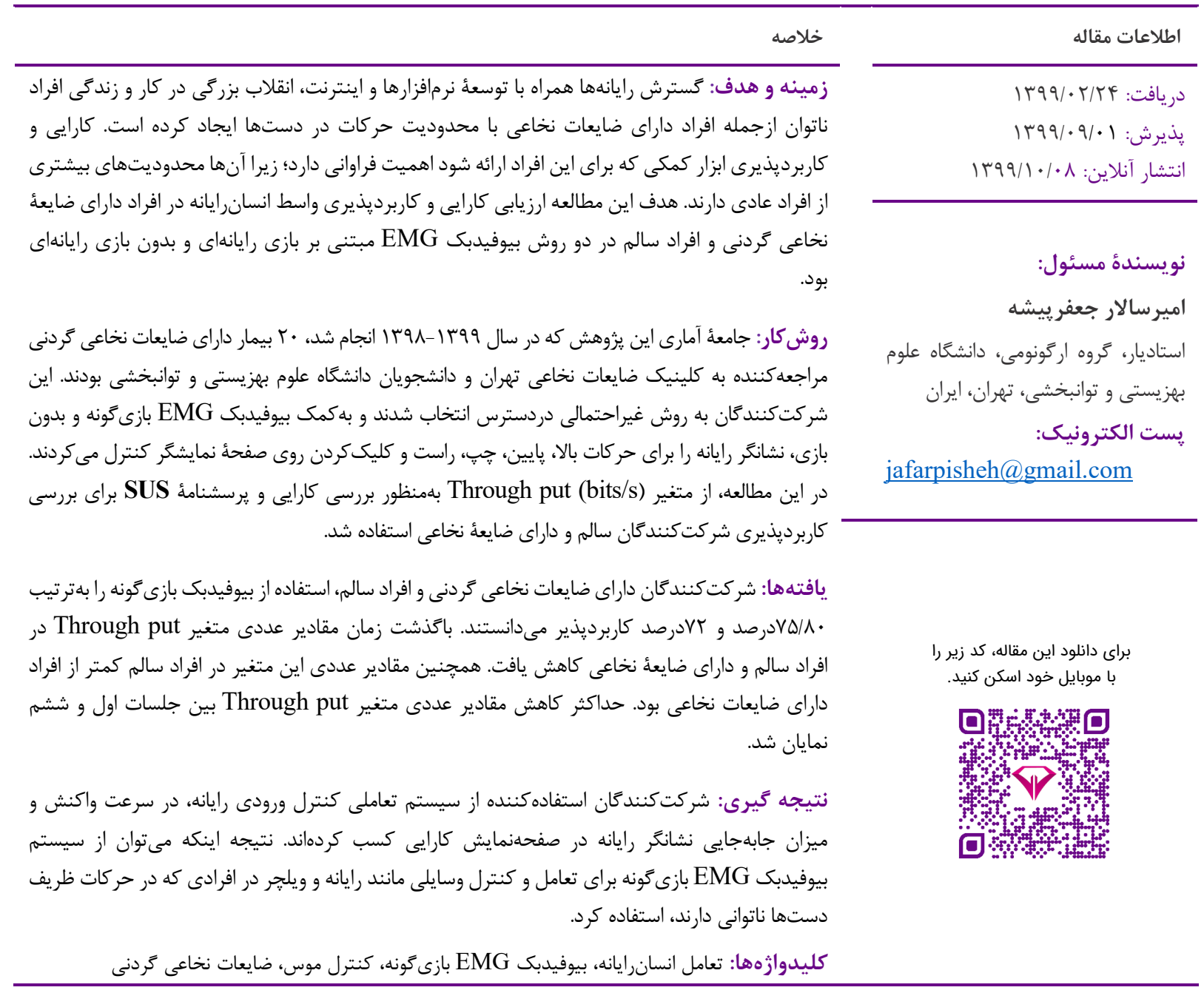

مقدمه

به SCI منجر مى شوند، تصادفات وسايل نقليه و افتادنهاست [1 [1]. شيوع و بروز SCI بهدليل ارتباط با آمارهاى منطقهایى و برخى
از مهمترين عوامل ايجادكننده اختلال و ناتوانى حركتى

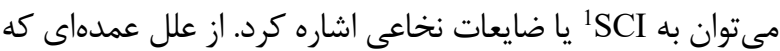


زيستى بدن اندازهيرى مىشود و به فرد بازخورد مىدهد تا

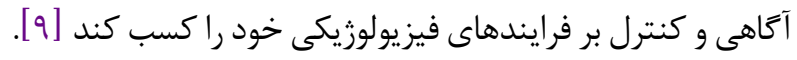
بيوفيدبك EMG

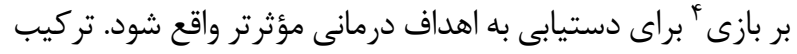

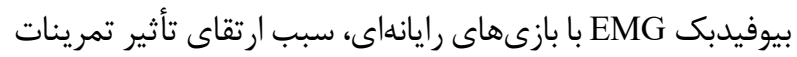

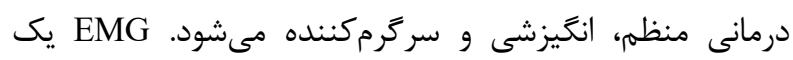

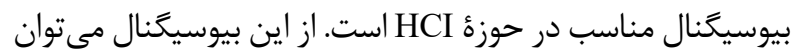

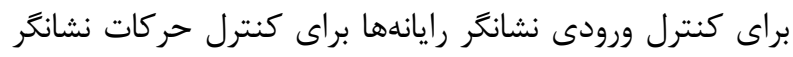

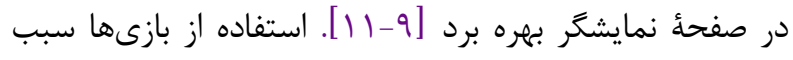

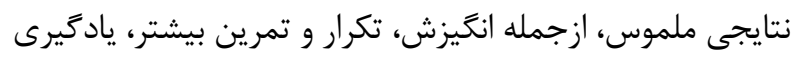

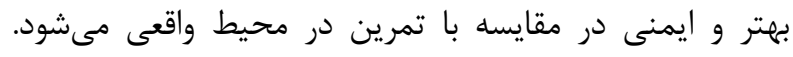

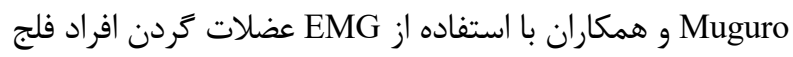

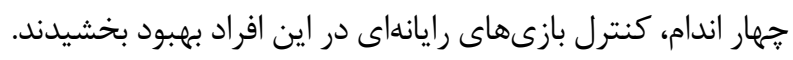

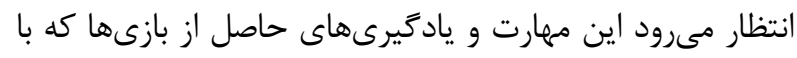

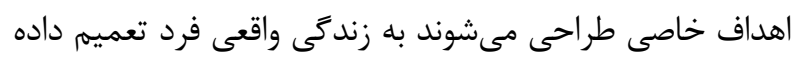

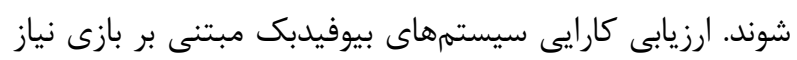

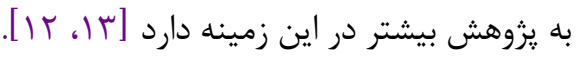

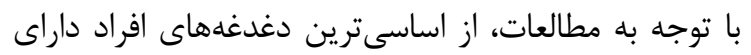

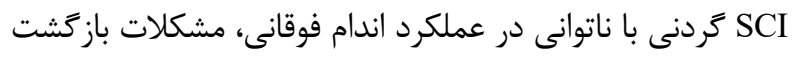

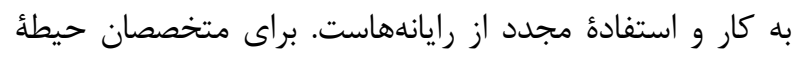

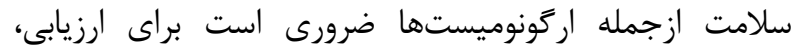

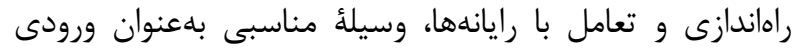

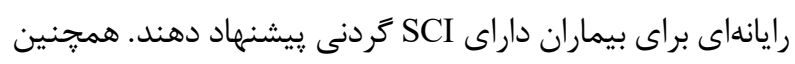

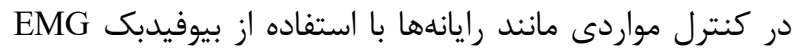
بايد ازنظر سرعت و دقت، يتانسيلى مشابه حركات طبيعى ايجاد

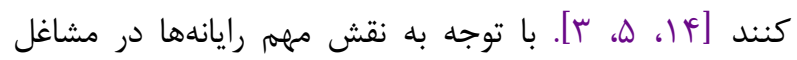

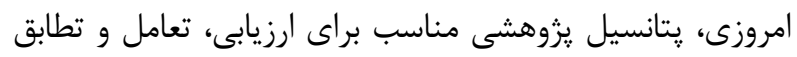
رايانها در افرادى با ناتوانىهاى دست، بلوئي كردنى شكل كرفته است. در اين يروهش، تأثير بهكاركيرى

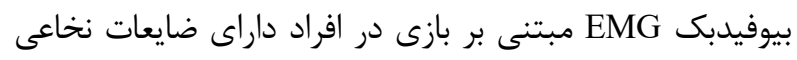

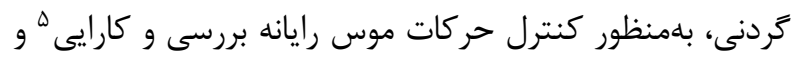
كاربرديذيرى

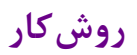

${ }^{4}$ Game-based

${ }^{5}$ Efficiency

${ }^{6}$ Usability
فاكتورهاى اجتماعىاقتصادى بسيار متغير است. آمارها نشان

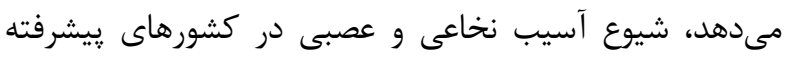

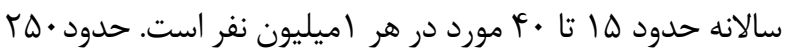

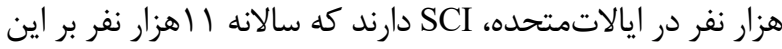

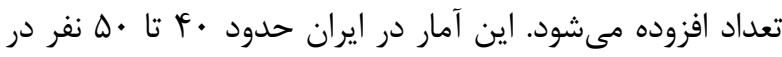

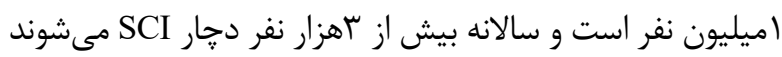

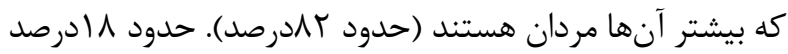
اين جمعيت شامل افراد داراى SCI كردنى هستند كه مشكلات

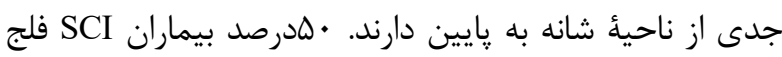

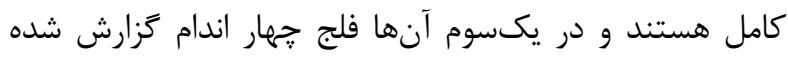
است. آسيب نخاعى كردنى با توجه به سطح آسيب، سبب ناتوانى

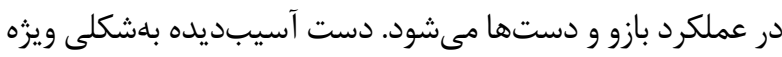

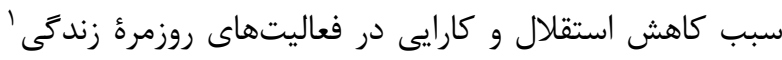
مىشود و به محدوديت در فعاليتهاى اجتماعىاقتصادى ازجمله

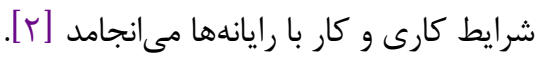

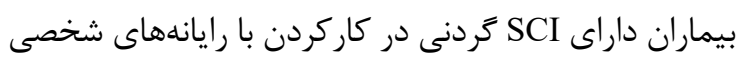
و ادارى مشكل دارند كه دليل اين امر، محدوديتهاى اندام فوقانى براى استفاده از صفحهكليد و موس است. اين افراد إداد

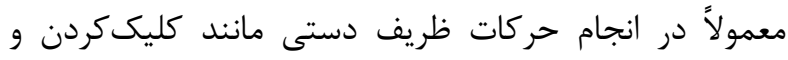

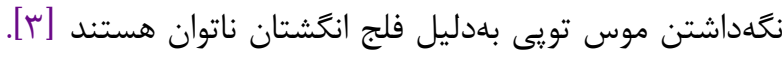
همجنين امروزه شاهد افزايش افرادى هستيم كه در بيشتر زمان كارىشان از رايانهها استفاده مى كنند. كسترش رايانها

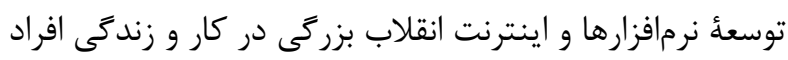
ناتوان ازجمله افراد داراى SCI با محدوديت حركتى ايجاد كرده

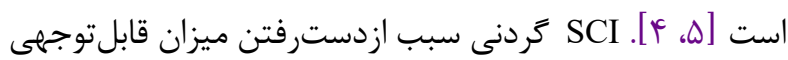
از عملكرد افراد مىشود كه اين ناتوانىها، بر خانواده، واحدهاى إنى

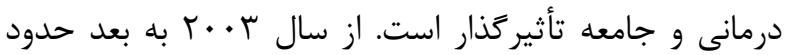

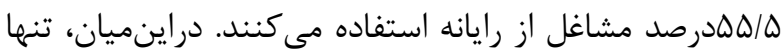

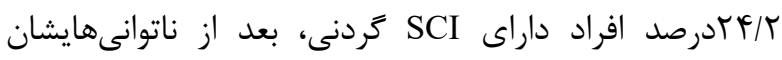
مىتوانند از رايانه براى كار و دسترسى به اينترنت استفاده كنند آندان

ئ ${ }^{2}$ تعامل ميان انسان و رايانه است كه اجازء كنترل انسان

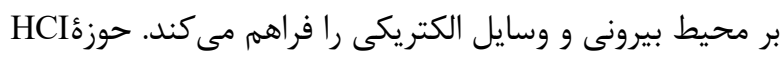

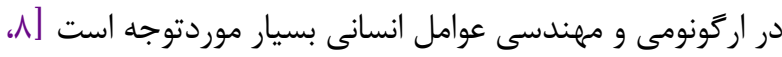
IV

${ }^{1}$ Activity daily living

${ }^{2}$ Human computer interface

${ }^{3}$ Electromyogram 
(قبل، حين و بعد) \& تست از آموزش و كار با بيوفيدبك بازى گونه

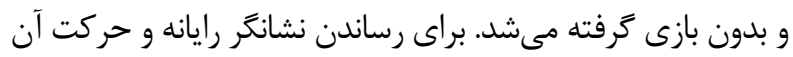

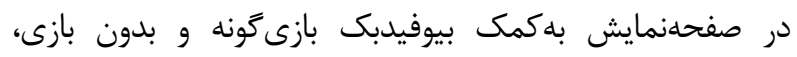
دايرههاى سبزرنكى بلعنوان اهداف طراحى شدند. اين دايرهها

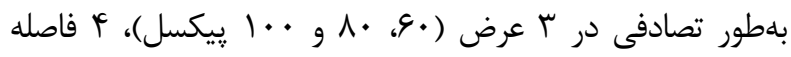

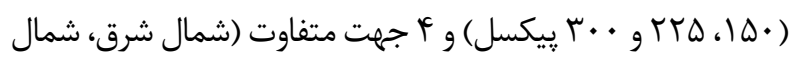
غرب، جنوب شرق و جنوب غرب) در صفحأ نمايشكر ظاهر شدند.

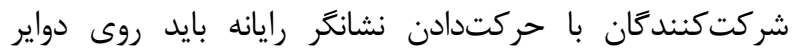

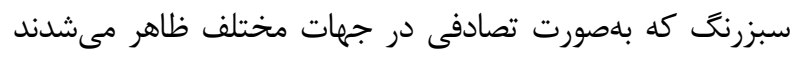

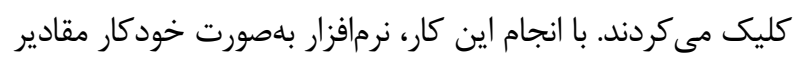

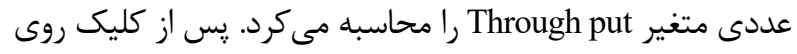

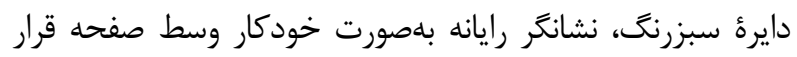

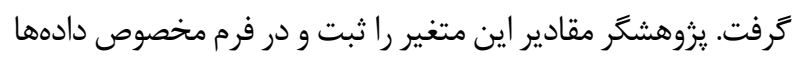

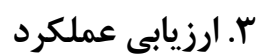

عملكرد كنترل نشانكر رايانه با متغير عملكردى ارزيابى شد؛

\section{متغير Through put}

برابر با شاخص سختى (ID) تقسيمبر زمان حركت (MT) به مديه سمت هدف موردنظر است. Through put نيز نسبت ميزان اطلاعات منتقلشده است. براى هر هدف مدف مورد آزمايش افراد

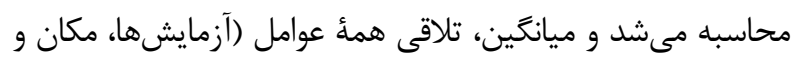

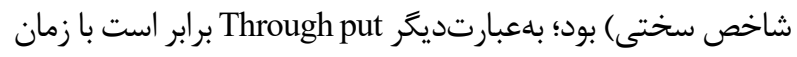

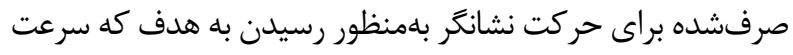

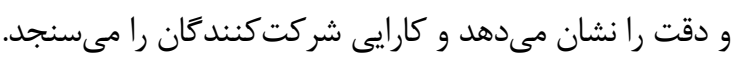

\section{$=$ ID/MT)bits/s (Through put}

جاخص سختى برابر با حركت نشانكر بهطرف يك هدف (دواير سبزرنگ) در صفحهنمايش دوبعدى است و فرمول محاسبة آن عبارت

\section{$\mathrm{ID}=\log _{2}(\mathrm{D} / \mathrm{W}+1)$}

لفاصلة مكان اصلى نشانكر تا مكان هدف و W عرض هدف

ج جن

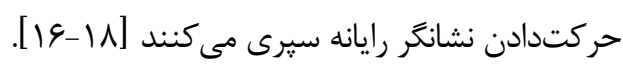

${ }^{2}$ Ashworth Scale

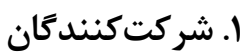

جامعة آمارى موردبررسى بيماران داراى ضايعات نخاعى گركان مراجعلكننده به كلينيك ضايعات نخاعى تهران و داندان دانشجويان

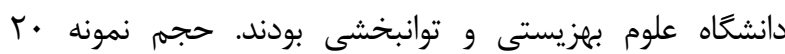

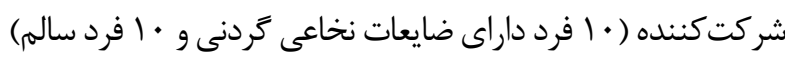

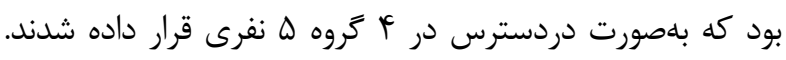

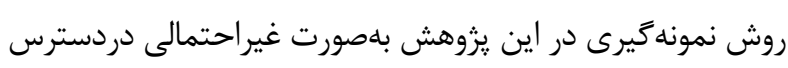

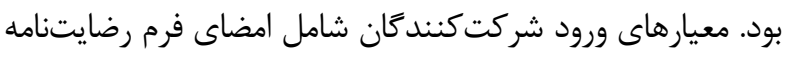

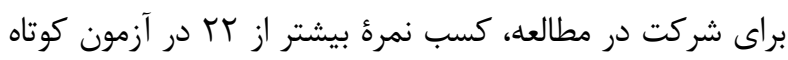

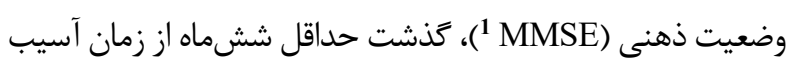

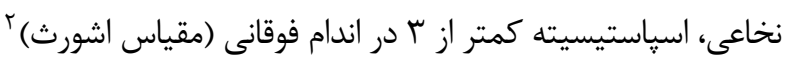

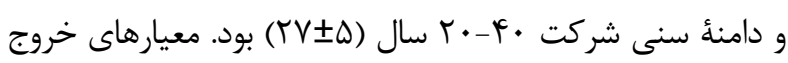

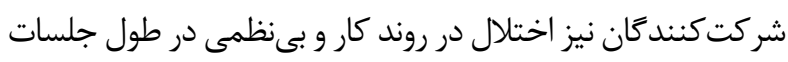

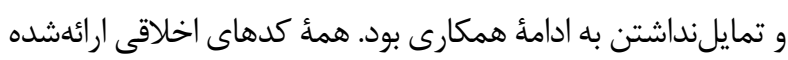

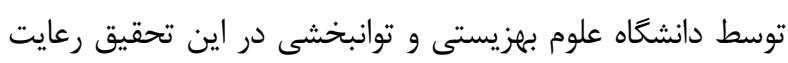

\section{r. طراحى ابزار و يردازش سيحنال}

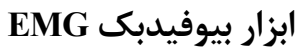

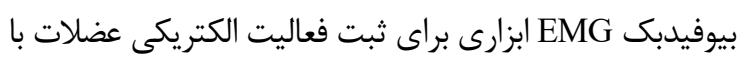

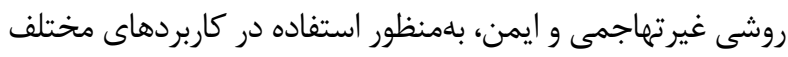

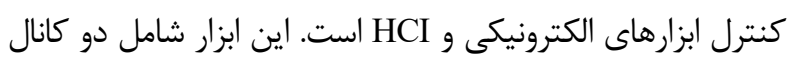

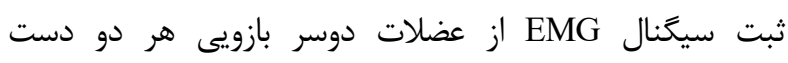

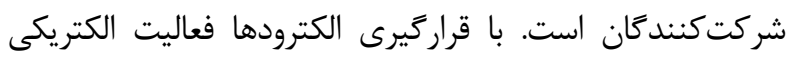

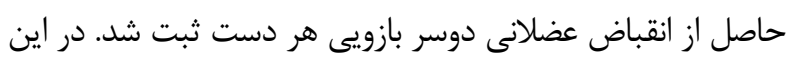

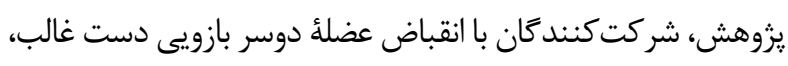

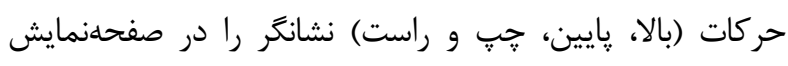

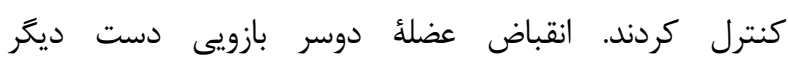

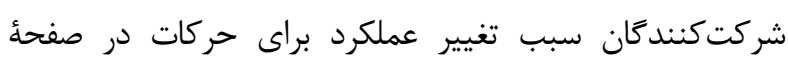

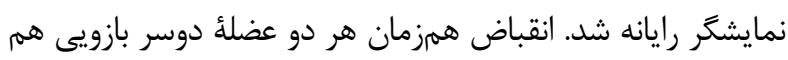

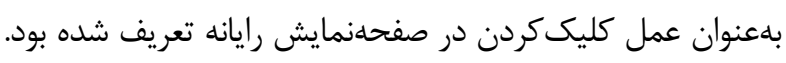

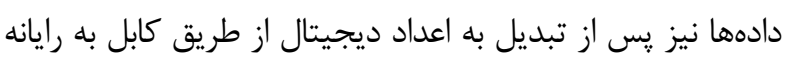

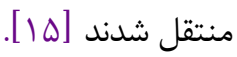

\section{EMG طراحى نرمافزار بيوفيدبك}

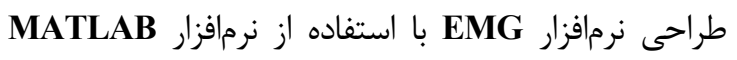

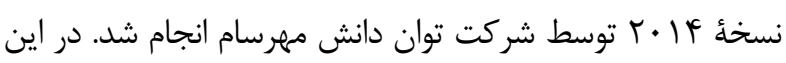

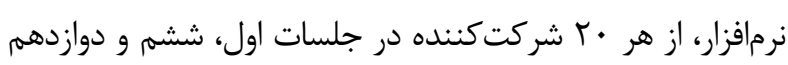

${ }^{1}$ Mini mental state examination 
هلدرصد نشاندهندة نبود رضايتمندى است. يايايى و روايى

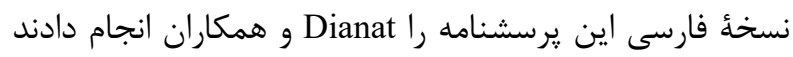
[rt-19]

\section{ه. دستور العمل مراحل اجرايى يخوهش

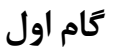

توضيحات شفاهى براى كنترل نشانكر رايانه با استفاده از

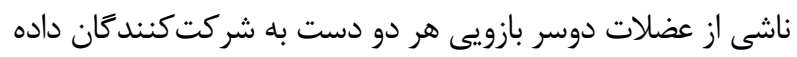

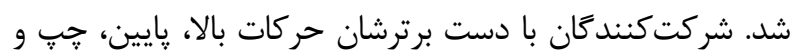

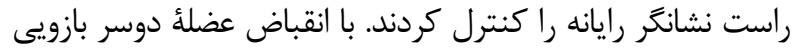

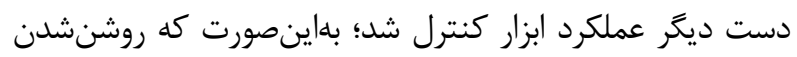

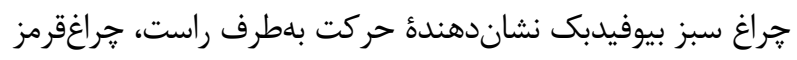

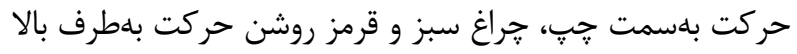

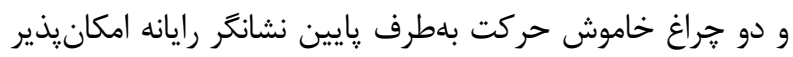

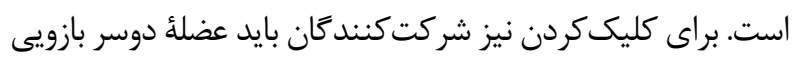

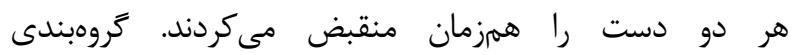
شركت كنندكان مطابق جدول ال صورت كرفت.

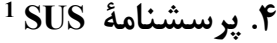
كاربرديذيرى يكى از مهمترين مشخصههاى كيفى است.

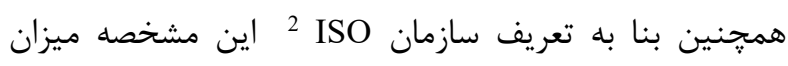

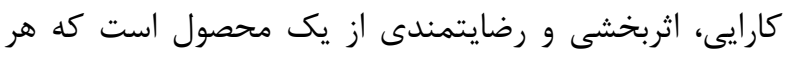

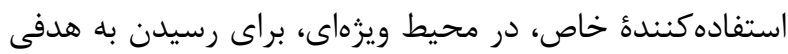

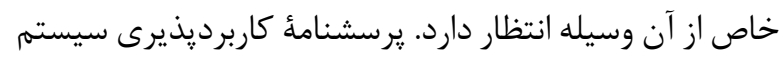

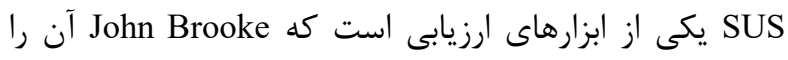
طراحى كرد. اين يرسشنامه شامل · ل1 سؤال است كه با استفاده

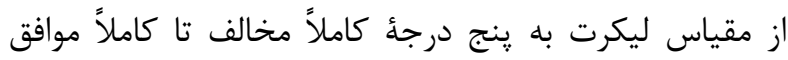

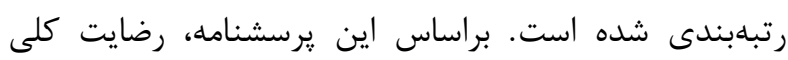

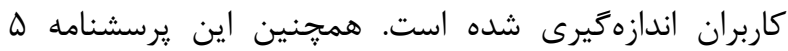

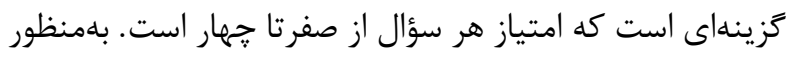

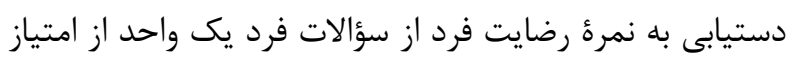

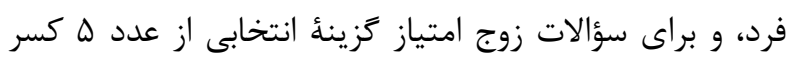

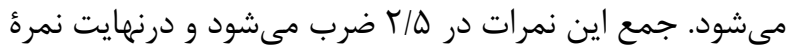

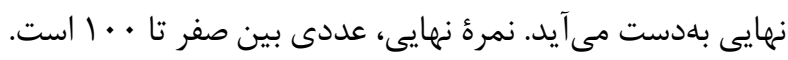

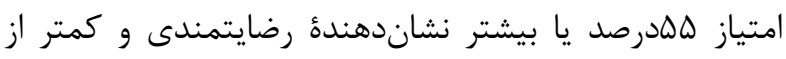

جدول ا. كروههاى شركتكننده بيوفيدبك EMG و بيوفيدبك بازى تونه

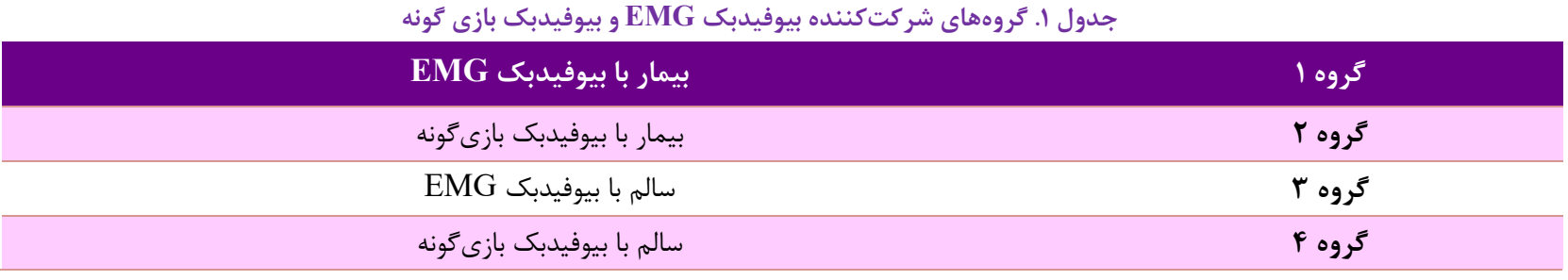

الكترودَذارى، سيخنال EMG از عضلات دوسر بازويى هر دو دست شركتكنندكان براى تعامل با نشانكر رايانه گرفته شد.

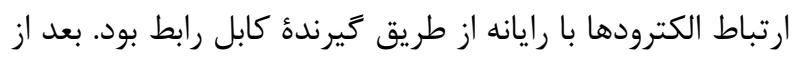
تبديل آنالوگ به ديجيتال اين سيخنال ها، الخوى فعاليت عضلات

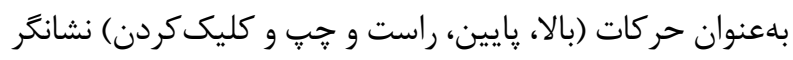

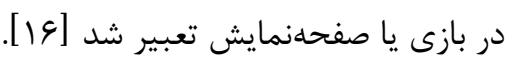

\author{
كام دوم \\ از شركت كنندگان درخواست شد روى صندلى ارگونوميكى دومى

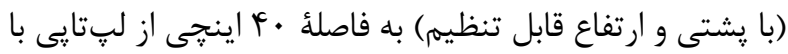

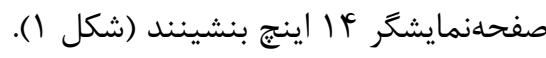 \\ شركت كنندكان هر دو دست خود را روى دستهُ صندلى قرار

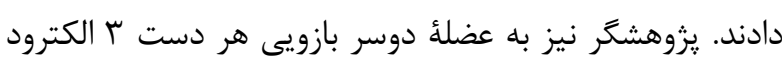

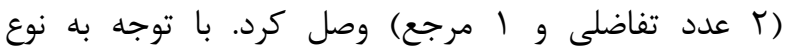




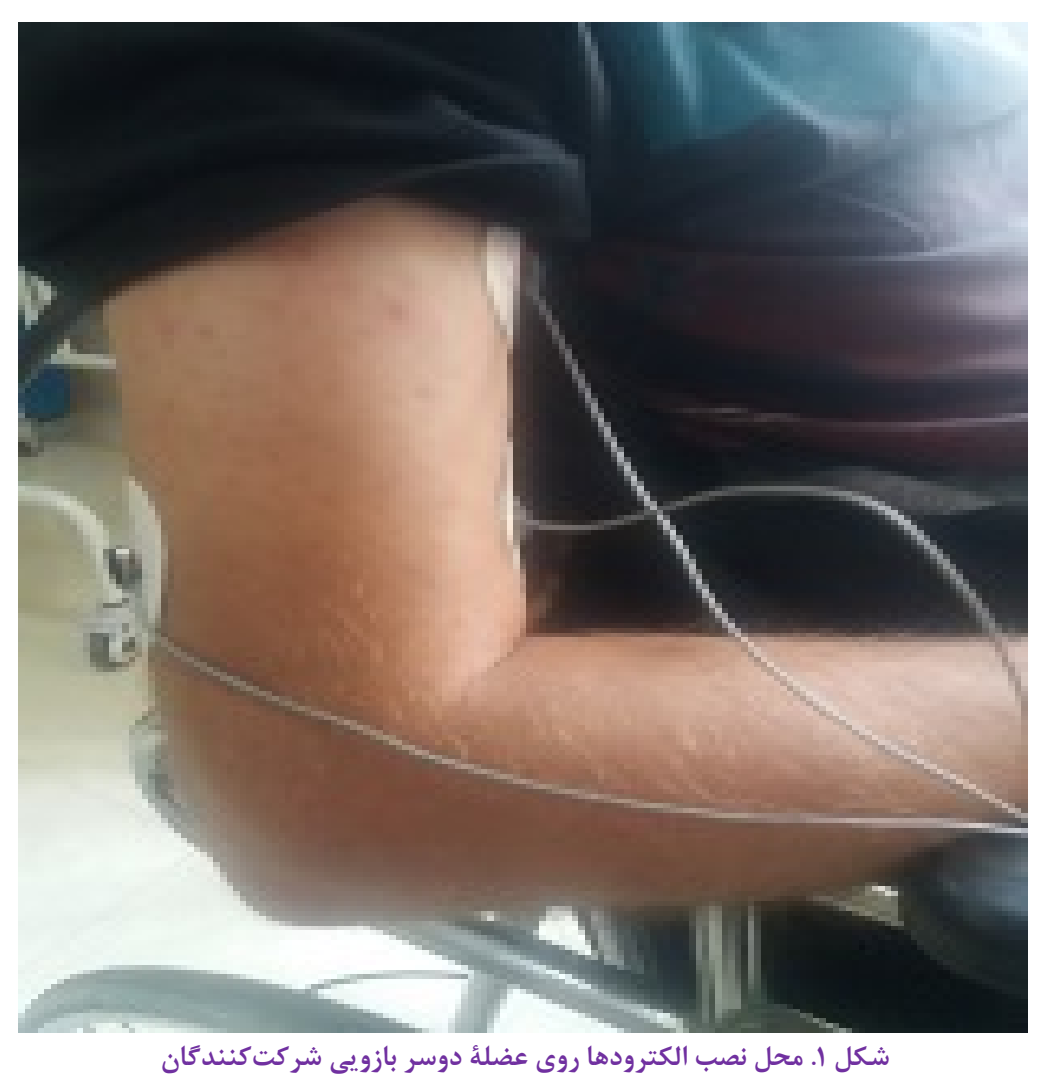

حركت نشانكر در صفحهنمايش حركت دهند و تمرين و تكرار كام سوم

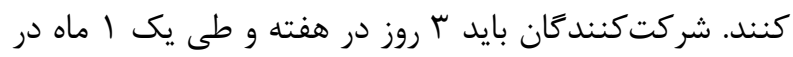

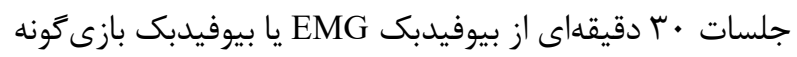

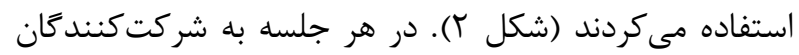

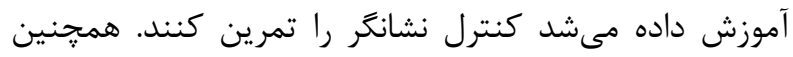

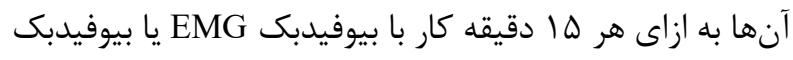

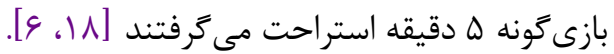

از شركت كنند كان در هر كروه خواسته شد به كمك عضلات

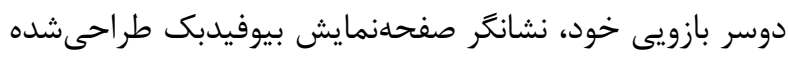

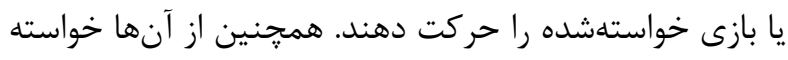

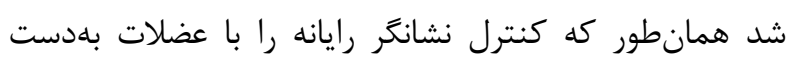

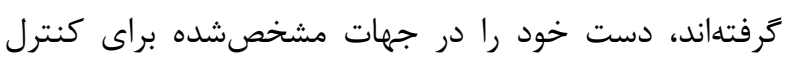

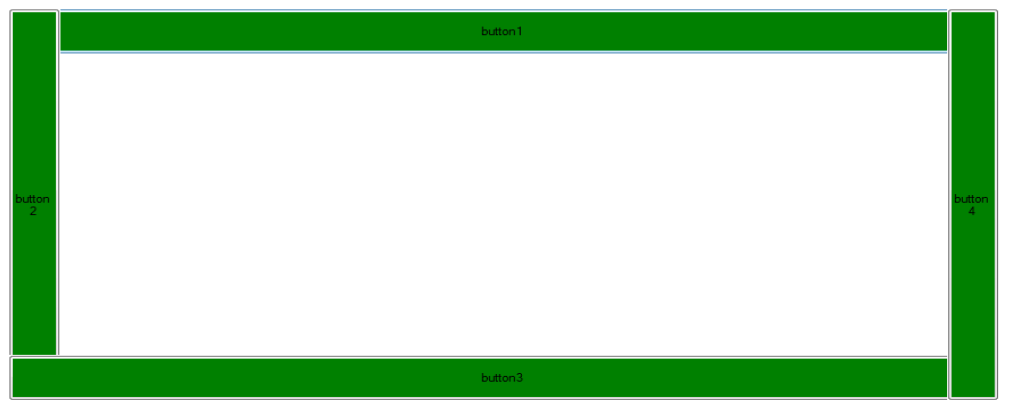

شكل r. تصوير بيوفيدبك EMG (شركتكنندًان بايد نشانكَر رايانه در اين حاشيئ سبزرنَّ را حركت مىدادند).

جهلوهشت تست براى كاركردن با بيوفيدبك EMG و

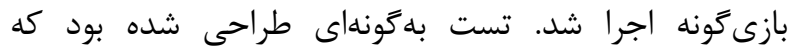

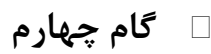


بيوفيدبك EMG و بيوفيدبك بازى كونه از شركت كنندكان كرفته شد (شكل r).

task number:23 $W=100 \quad D=225$

200.767784119749

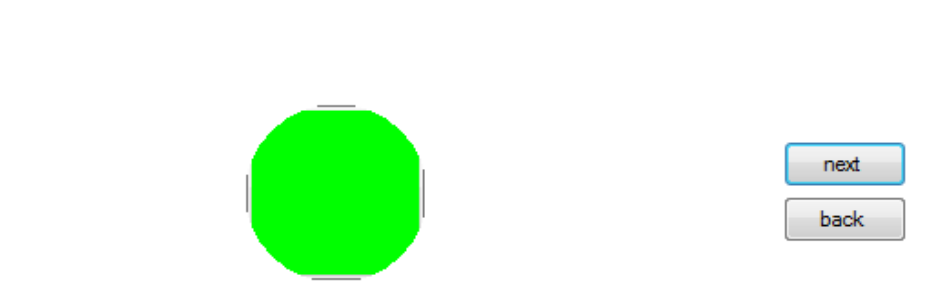

شركت كنندكان مىبايست نشانكر را روى دواير سبزرنغ با اندازه

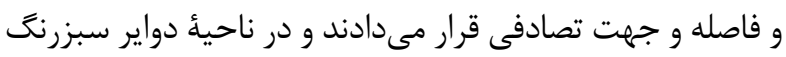

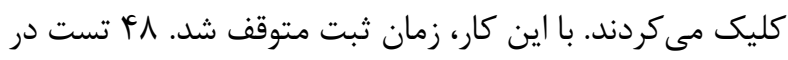

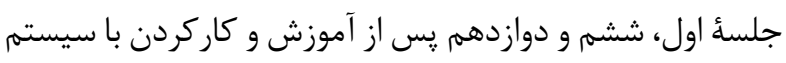

\begin{abstract}
(200767041970
\end{abstract}
شكل r. صفحهنمايش تست (شركت كنند كًان بايد نشانكر رايانه را به دواير سبزرنكَ مىرساندند و كليك مى كردند).

\begin{abstract}
مركز ثبت شد. براى جلوكيرى از تأثير خستخى عضلات
口

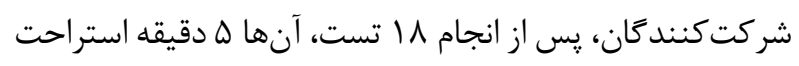
دادهاى متغير Through put شركت كنندكان در هر فينمان

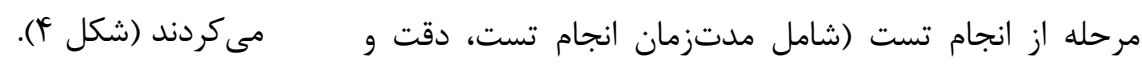

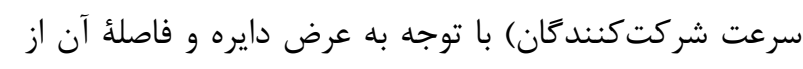

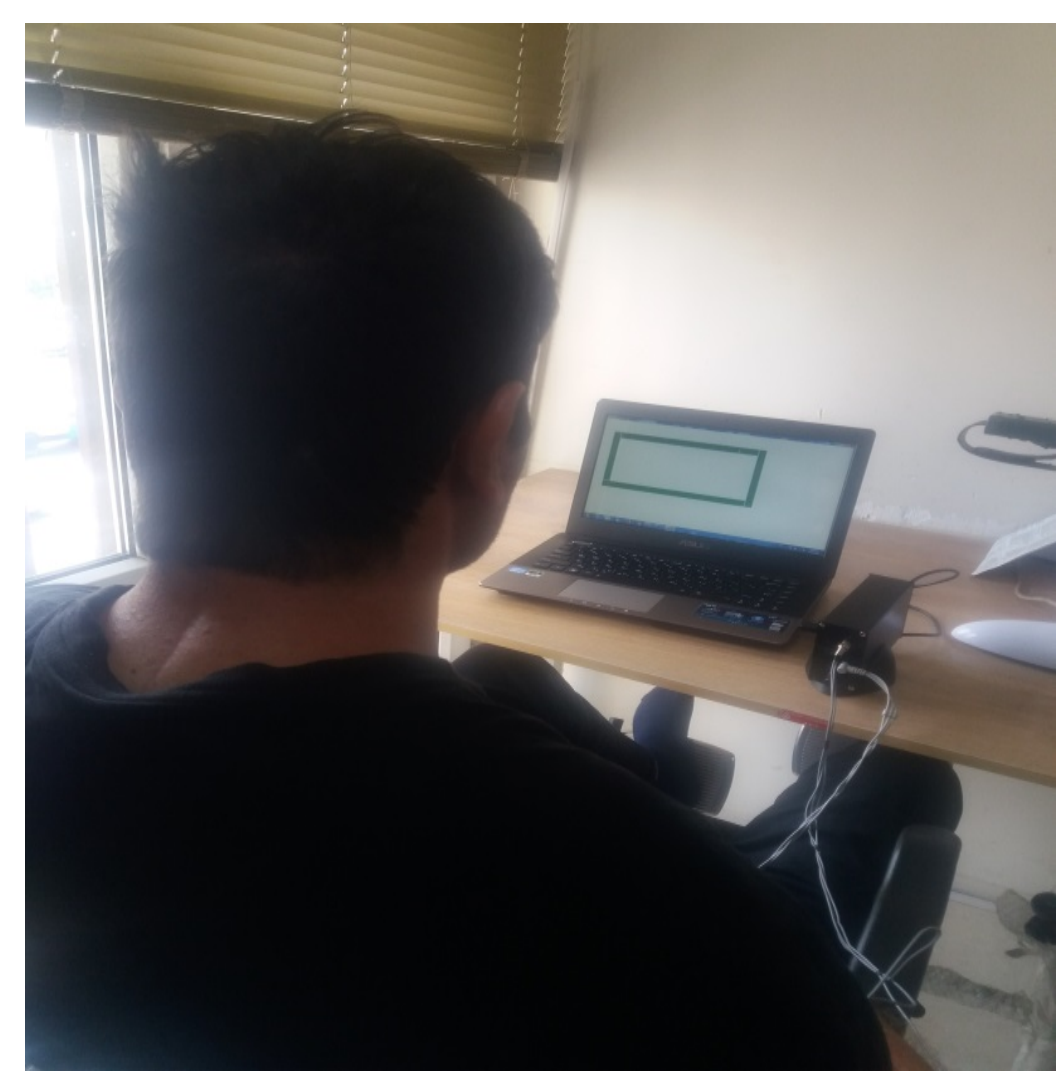

شكل F. كار با بيوفيدبك EMG 


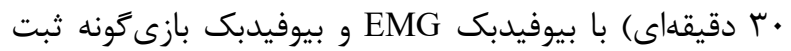

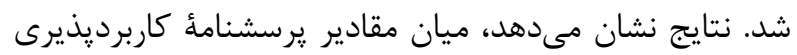

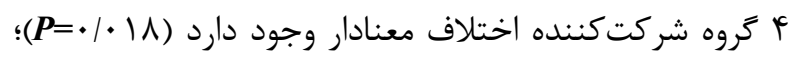

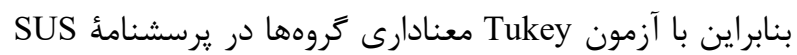

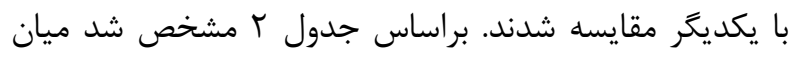

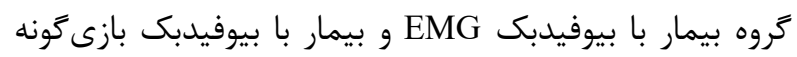

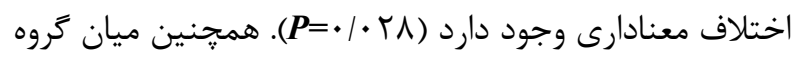

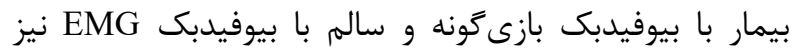

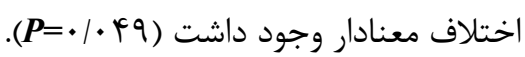

9. آناليز آمارى

بdمنظور تجزيدوتحليل دادهها از نرمافزار SPSS نسخئ سب إن استفاده شد. براى توصيف نوم نو (SPSS Inc., Chicago, Ill., USA) دادهها نيز از شاخصهاى آمارى مانند ميانگين، انحراف معيار و

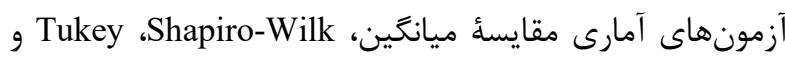

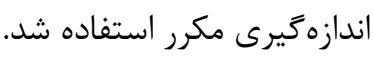

بافته ها

دادهها از \& ₹روه ه نفرى شركت كنند ششم و دوازدهم، بعد از يك ماه كار و آموزش (هفتهاى بـ جلسئ

جدول r. مقايسة معنادارى ميان F Fَروه شركت كننده در يرسشنامهٔ

\begin{tabular}{|c|c|c|c|}
\hline P-value & اختلاف ميانگين & & \\
\hline$\cdot / \cdot r \Lambda$ & $-11 / \ldots *$ & بيمار با بيوفيدبك بازى گونه & \multirow{3}{*}{ بيمار با بيوفيدبك } \\
\hline.$/ 991$ & $-1 / \cdots$ & سالم با بيوفيدبكEMG & \\
\hline$\cdot / T \cdot V$ & $-V / T \cdots$ & سالم با بيوفيدبك بازى ₹ونه & \\
\hline$\cdot / \cdot r \Lambda$ & $11 / \cdots *$ & بيمار با بيوفيدبك & \multirow{3}{*}{ بيمار با بيوفيدبك بازى گونه } \\
\hline$\cdot 1 \cdot 4 q$ & $1 \cdot 1 \ldots *$ & سالم با بيوفيدبكEMG & \\
\hline$\cdot / V \cdot 1$ & 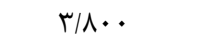 & سالم با بيوفيدبك بازى گونه & \\
\hline.$/ 991$ & $1 / \cdots$ & بيمار با بيوفيدبك & \multirow{3}{*}{ سالم با بيوفيدبك EMG } \\
\hline$\cdot 1 \cdot 4 q$ & $-1 \cdot 1 \cdot \ldots *$ & بيمار با بيوفيدبك بازى گونه & \\
\hline$\cdot / 419$ & $-9 / T \cdots$ & سالم با بيوفيدبك بازى گونه & \\
\hline$\cdot / T \cdot V$ & $V / T \cdot \cdots$ & EMG بيمار با بيوفيدبك & \multirow{3}{*}{ سالم با بيوفيدبك بازى } \\
\hline$\cdot / V \cdot 1$ & $-r / \Lambda \cdots$ & بيمار با بيوفيدبك بازى گونه & \\
\hline 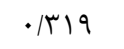 & $\varphi / r \cdot$. & سالم با بيوفيدبك EMG & \\
\hline
\end{tabular}

براساس جدول با، تأثير زمان درون آزمودنىها بر متغير Through put

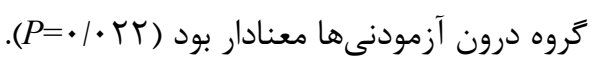

براى بررسى معنادارى ميان مقادير متغير Through put در

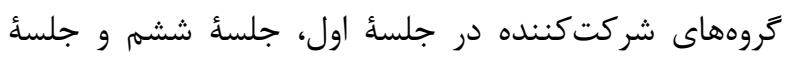

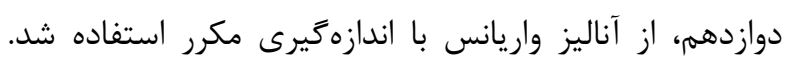

جدول گ. تحليل واريانس با اندازهَيرى مكرر جلسةُ اول، جلسهُ ششم و جلسهُ دوازدهم متغير TP در F Fروه شركت كننده

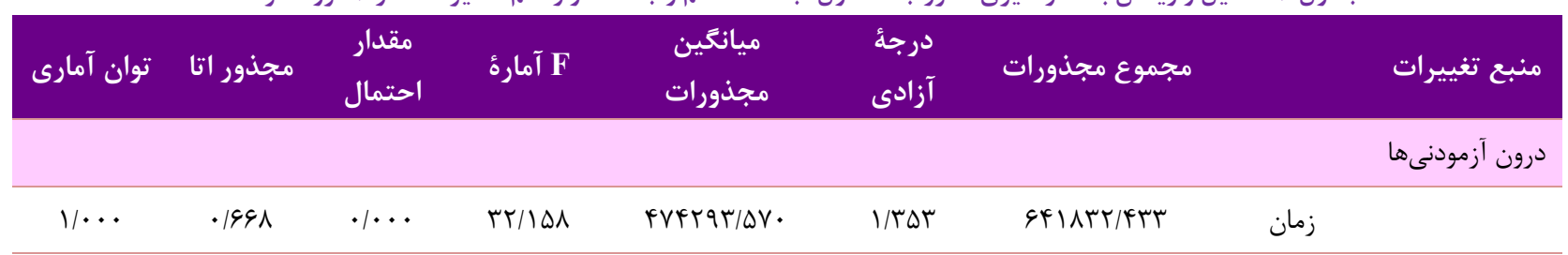




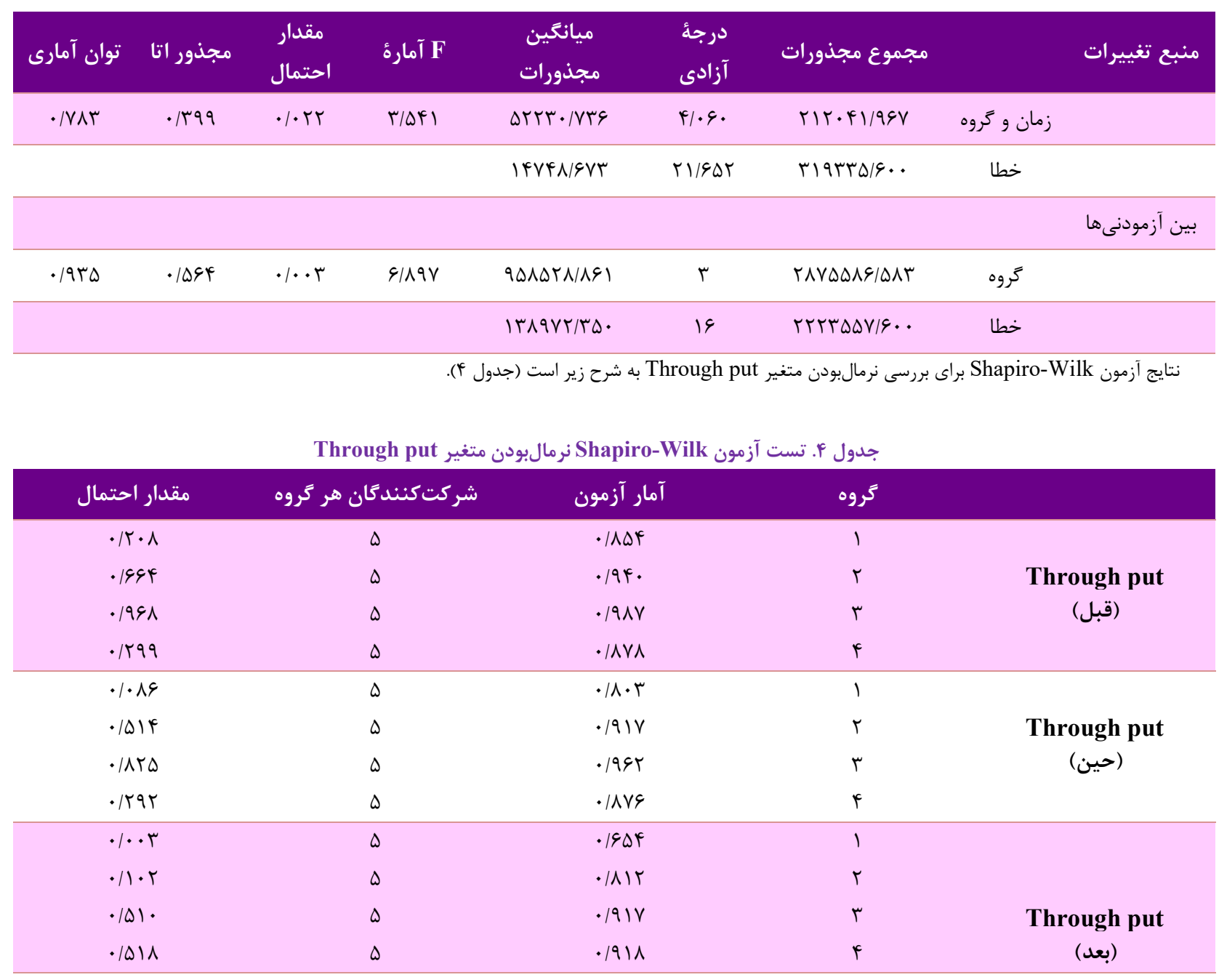

با بيوفيدبك EMG اختلاف معنادارى وجود دارد (9 + •|•=. در جدول ه، معنادارى متغير Through put در ميان F كروه

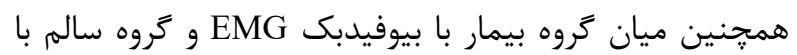
شركت كننده مقايسه شده است. با توجه به اين جدول، بين معندين

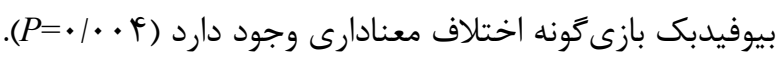

جدول ه. مقايسُٔ معنادارى درونَروهى متغير Through put

\begin{tabular}{|c|c|c|c|}
\hline P-value & اختلاف ميانكَين & ترووه & \\
\hline$\cdot 11 \cdots$ & $r$ rq/·V & بيمار با بيوفيدبك بازى گونه & \multirow{3}{*}{ بيمار با بيوفيدبك } \\
\hline $.1 . .9$ & $\Delta \cdot V / 9 \mu^{*}$ & سالم با بيوفيدبكEMG & \\
\hline$\cdot 1 \cdot \cdot F$ & $\Delta G \cdot / 1 \mu^{*}$ & سالم با بيوفيدبك بازى گونه & \\
\hline$\cdot 11 \cdots$ & $-r r q / \cdot V$ & بيمار با بيوفيدبكEMG & \multirow{3}{*}{ بيمار با بيوفيدبك بازى } \\
\hline.$|91|$ & IEN/AV & سالم با بيوفيدبكEMG & \\
\hline$\cdot /$ rqf & $T T Y / \cdot V$ & سالم با بيوفيدبك بازى گونه & \\
\hline $.1+.9$ & $-Q \cdot V / q \mu^{*}$ & بيمار با بيوفيدبكEMG & \multirow{3}{*}{ سالم با بيوفيدبكEMG } \\
\hline .1911 & $-19 N / \Lambda V$ & بيمار با بيوفيدبك بازى گونه & \\
\hline$\cdot / 91$ & $\Delta T / T$. & سالم با بيوفيدبك بازى گونه & \\
\hline
\end{tabular}




\begin{tabular}{|c|c|c|c|}
\hline P-value & اختلاف ميانَين & تروه - ت ك & \\
\hline$\cdot / \cdot f$ & $-\Delta \varepsilon \cdot / 1 \mu$ & بيمار با بيوفيدبكEMG & \multirow{3}{*}{ سالم با بيوفيدبك بازى } \\
\hline - /rqq & $-r Y I / \cdot V$ & بيمار با بيوفيدبك بازى گونه & \\
\hline$\cdot 191$. & $-\Delta T / T$. & سالم با بيوفيدبكEMG & \\
\hline \multirow{2}{*}{\multicolumn{4}{|c|}{ 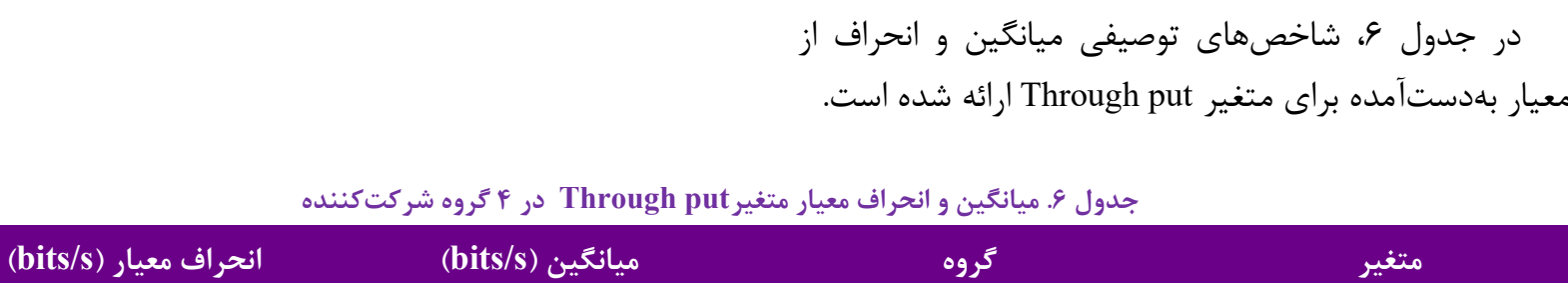 }} \\
\hline & & & \\
\hline$r \cdot 1 / \Delta \cdot r$ & $1.91 / 1 \cdot$ & بيمار با بيوفيدبكEMG & \\
\hline$r \wedge r / q \cdot \Lambda$ & $9 \Delta T / \Lambda$. & بيمار با بيوفيدبك بازى گونه & \\
\hline MN/VYY & rV $/ \cdot \cdot$ & سالم با بيوفيدبكEMG & جلسأ اول \\
\hline $1 \cdot V / 9 \& Y$ & $r \cdot 1 / 9$. & سالم با بيوفيدبك بازى گونه & \\
\hline r^९/199 & $\Delta 9 V / \cdot \Delta$ & | F F F & مجموع \\
\hline$F F \cdot / \Lambda \Delta q$ & $V \cdot \Delta / \Lambda$. & بيمار با بيوفيدبكEMG & \\
\hline$q \Delta / r q$. & rAr/T. & بيمار با بيوفيدبك بازى گونه & \\
\hline re/VqV & $r \Delta \Delta / \cdot \cdot$ & سالم با بيوفيدبكEMG & جلسأ ششم \\
\hline$F F / V \Delta D$ & TY\&/. & سالم با بيوفيدبك بازى گونه & \\
\hline$r \wedge r / l r q$ & rqv/Q. & 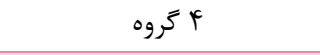 & مجموع \\
\hline rqD/IrT & GFF/F. & بيمار با بيوفيدبكEMG & \\
\hline$\varepsilon Y / \Delta Q$. & $r \Delta V / \Lambda$. & بيمار با بيوفيدبك بازى گونه & \\
\hline$\Delta \varphi / \cdot \Lambda r$ & TET/T. & سالم با بيوفيدبكEMG & جلسهُ دوازدهم \\
\hline$\Delta V / \varepsilon \Delta F$ & $|\wedge F| \cdots$ & سالم با بيوفيدبك بازى گونه & \\
\hline$r \Delta \Lambda / 9 \Delta F^{r}$ & rGY/l. & F F F F & مجموع \\
\hline
\end{tabular}

متغير Through put در † ₹روه شركت كننده در جلسة اول، جلسأ ششم و جلسئ دوازدهم با استفاده از بيوفيدبك EMG و بيوفيدبك بازى گونه قابل مشاهده است.
نتايج نشان مىدهد، ميانگين كلى متغير Through put در ץ ₹روه كاهش يافته است؛ يعنى با حذشت زمان شركت كنند

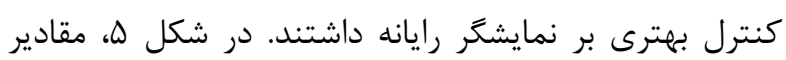




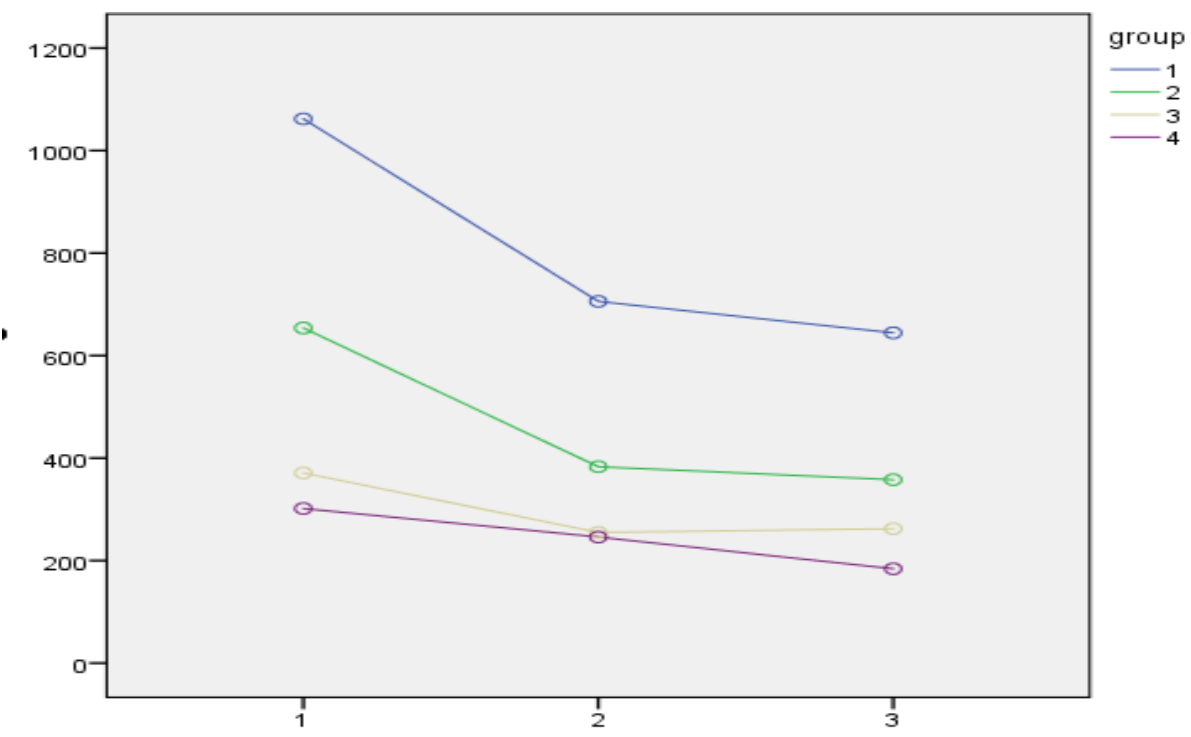

شكل ه. مقايسٔ ميانغَين متغير Through put در جلسات اول، ششم و دوازدهم \& كروه شركتكننده

نشاندهندة بيشترين آموزش و يادكيرى حركتى استفاده از بيوفيدبك

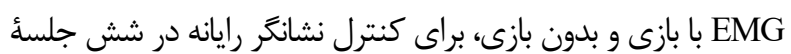

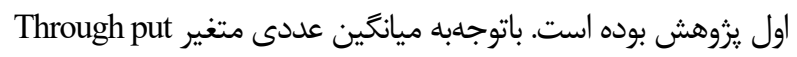

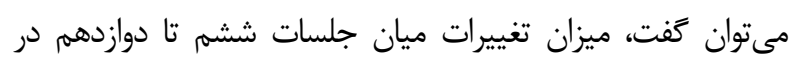

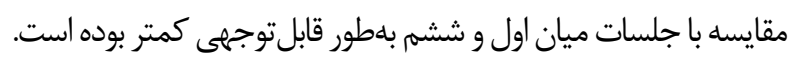
شايد بتوان كفت بهدليل كنترل حركتى ضعيف بيماران داراى ضايعات

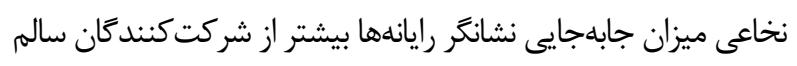

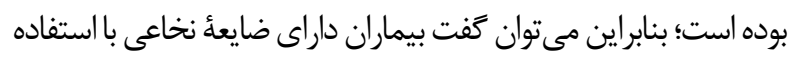

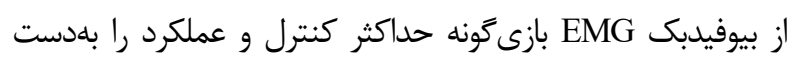
آوردهاند. يِيشنهاد مىشود براى بهبود دقت و كنترل عضلانى دقيقتر بيماران ضايعؤ نخاعى از بيوفيدبك EMG بازى گُونه استفاده شود. نتايج

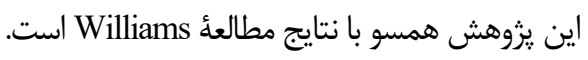

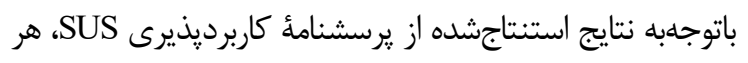

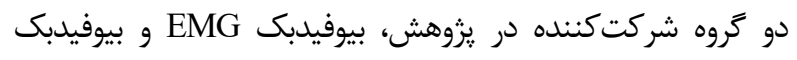

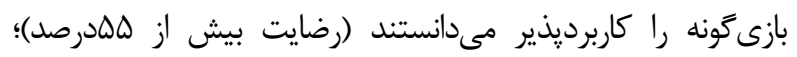

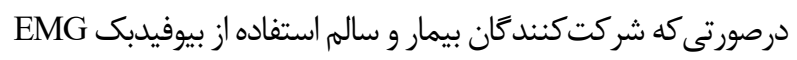

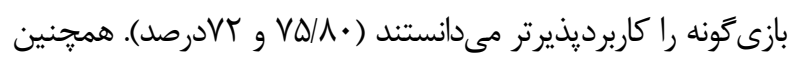
بيوفيدبك EMG مبتنى بر بازى در افراد داراى ضايعات نخاعى كردنى مارئي

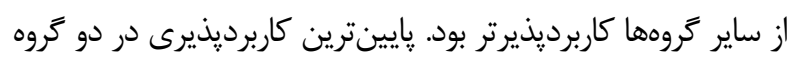

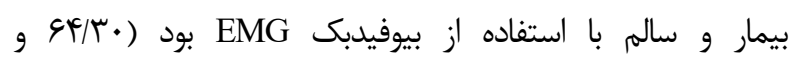

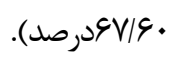

هدف اين يزوهش، بررسى كارايى و كاربرديذيرى بيوفيدبك

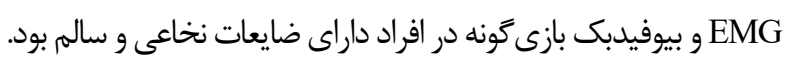

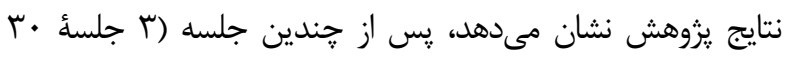

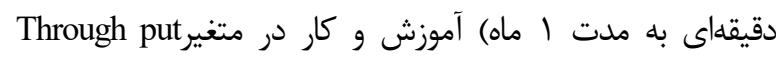

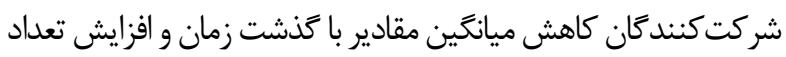

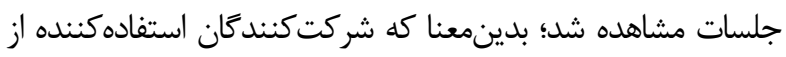
سيستم تعاملى كنترل ورودى رايانه، در سرعت واكنش و ميزان ماندان

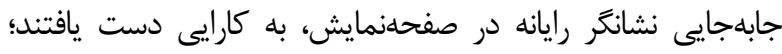
بنابراين هرجه زمان بيشترى از واسط انسانرايانه استفاده شود، داند

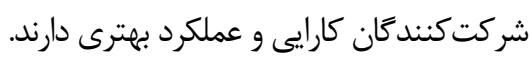

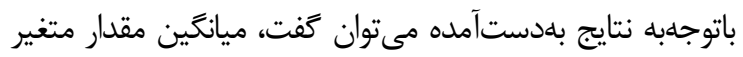

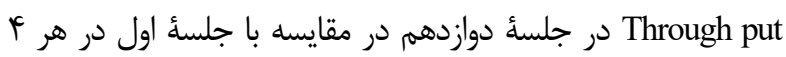

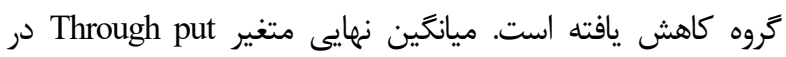

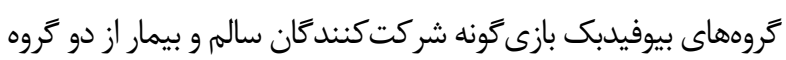

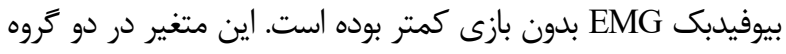

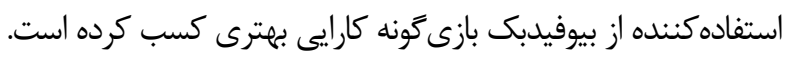

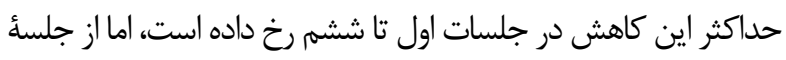

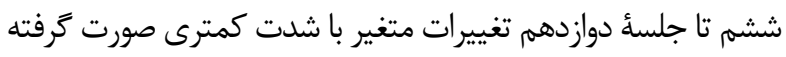

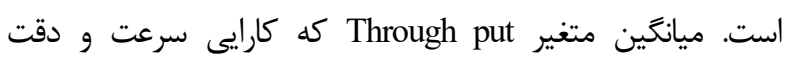

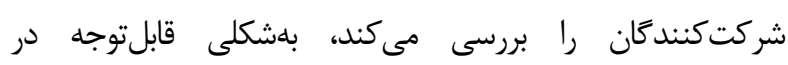

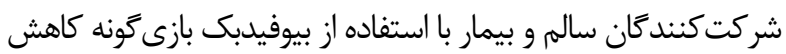
عددى داشته است.

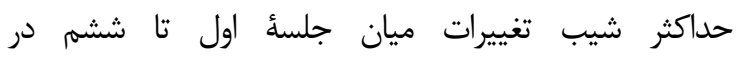
شركتكنندكان سالم و داراى SCI ايجاد شده است. اين موضوع 
استفاده از بيوفيدبك EMG بازى گونه تلاش و استفاده بيشترى در شركت كنندكان سالم و داراى ضايعهُ نخاعى گردنى قابل مشاهده بود. شركتكنندكان نيز استفاده از اين نوع بيوفيدبك رانى كاربرديذيرتر بيان كردند. مىتوان كارايى و كاربرديذيرى استفاده از

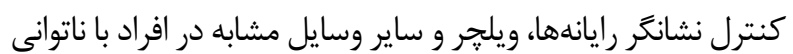
در دستها را با استفاده از بيوفيدبك EMG بازى گئونه افزايش داد.

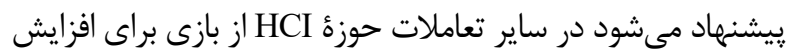
كارايى و كاربرديذيرى استفاده شود.

\section{تقدير و تشكر}

نويسندكان اين مقاله مراتب تقدير و تشكر خود را از همئ شركت كنند ارائهشده از سوى دانشخاه علوم بهزيستى و توانبخشى مطابق با كد IR.USWR.REC.1397.044 در اين تحقيق رعايت شد.

$$
\text { تعارض منافع }
$$

بين نويسندگان هيجزَّه تعارضى در منافع وجود ندارد.

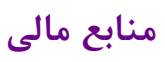

منابع مالى اين مطالعه توسط نويسندكان تامين شده است.

\section{References}

1. Pinto SM, Galang G. Concurrent SCI and TBI: Epidemiology, Shared Pathophysiology, Assessment, and Prognostication. Curr. Phys. Med. Rehabil. Rep. 2016 Mar 1;4(1):71-9. [DOI:10.1007/s40141-0160109-6]

2. Kloosterman MG, Snoek GJ, Jannink MJ. Systematic review of the effects of exercise therapy on the upper extremity of patients with spinal-cord injury. Spinal Cord 2009 Mar;47(3):196-203. [DOI:10.1038/sc.2008.113] [PMID]

3. Tanimoto Y, Rokumyo Y, Furusawa K, Tokuhiro A, Suzuki Y, Takami K, Yamamoto H. Development of a computer input device for patients with tetraplegia. Comput. Stand. Interfaces. 2005 Dec 1;28(2):166-75. [DOI:10.1016/j.csi.2005.01.018]

4. Park SY, Yoo WG. Effect of EMG-based feedback on posture correction during computer operation. J. Occup. Health. 2012 Jul;54(4):271-7. [DOI:10.1539/joh.120052-OA] [PMID]

\section{نتيجه گَيرى}

در مقايسه با ساير سيستمهاى HCI، استفاده از بيوفيدبك

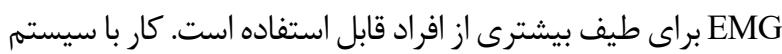

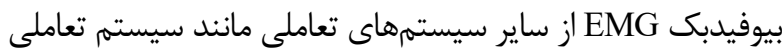
ردياب سر و جشمى آسانتر و ازنظر اقتصادى بلصرفهتر است. سيستم بيوفيدبك EMG و سيستم بيوفيدبك بازى هندين جلسه كار و آموزش قابل استفاده است. براساس نتايج كاربرديذيرى شركت كنندگان مىتوان عفت، هر دو واسط انسانرايانة بيوفيدبك EMG و بيوفيدبك بازى گونه، كاربرديذيرى دارند. بهدليل كنترل عضلانى دقيقتر دو گروه افراد سالم، مقادير باديري عددى متغير اندازهخيرىشده درمجموع كمتر نشان داده شد. كار با اين سيستم تعاملى براى افراد داراى SCI گردنى به علت كنترل حركتى ضعيفتر نسبت به افراد سالم دشوارتر است. افراد SCI

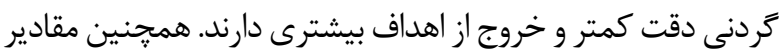

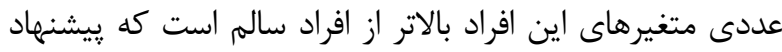

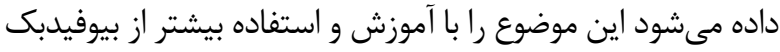

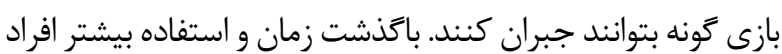
كردنى از واسط انسانرايانه، كارايى و كاربرديذيرى اين تعامل SCI براى اين افراد بهطور قابلتوجهى بهبود مى يابد.

تركيب بيوفيدبك EMG با بازى سبب افزايش انگيزه و

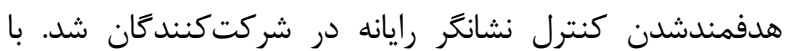

5. Kim DG, Lee BS, Lim SE, Kim DA, Hwang SI, Yim YL, Park JM. The selection of the appropriate computer interface device for patients with high cervical cord injury. Ann. Rehabil. Med. 2013 Jun;37(3):443. [DOI:10.5535/arm.2013.37.3.443] [PMID] [PMCID]

6. Williams MR, Kirsch RF. Evaluation of head orientation and neck muscle EMG signals as threedimensional command sources. J NEUROENG REHABIL. 2015;12(1):25. [DOI:10.1186/s12984-0150016-6] [PMID] [PMCID]

7. Yang X, Chen G, editors. Human-computer interaction design in product design. 2009 First International Workshop on Education Technology and Computer Science; 2009: IEEE. [DOI:10.1109/ETCS.2009.359]

8. Barreto A, Scargle S, Adjouadi M. A practical EMGbased human-computer interface for users with motor disabilities. 2000. [DOI:10.1145/569270.569272]

9. Pop-Jordanova N, Demerdzieva A. Biofeedback training for peak performance in sport-case study. Open 
Access Maced. J. Medical Sci. 2010 Jun 15;3(2):113-8. [DOI:10.3889/MJMS.1857-5773.2010.0098]

10. Bhandari R, Parnandi A, Shipp E, Ahmed B, GutierrezOsuna R. Music-based respiratory biofeedback in visually-demanding tasks. InNIME 2015 Jan 1.

11. Neblett R. Surface electromyographic (SEMG) biofeedback for chronic low back pain. InHealthcare 2016 Jun (Vol. 4, No. 2, p. 27). Multidisciplinary Digital Publishing Institute. [DOI:10.3390/healthcare4020027] [PMID] [PMCID]

12. Yoo JW, Lee DR, Sim YJ, You JH, Kim CJ. Effects of innovative virtual reality game and EMG biofeedback on neuromotor control in cerebral palsy. Biomed Mater Eng. 2014 Jan 1;24(6):3613-8. [DOI:10.3233/BME141188] [PMID]

13. Muguro JK, Sasaki M, Matsushita K, Njeri W, Laksono PW, Suhaimi MS. Development of neck surface electromyography gaming control interface for application in tetraplegic patients' entertainment. InAIP Conference Proceedings 2020 Apr 13 (Vol. 2217, No. 1, p. 030039). AIP Publishing LLC.

14. Borish CN, Bertucco M, Sanger TD. Effect of target distance on controllability for myocontrol. Int. J. Hum. Comput. $\quad 2020 \quad$ Aug 1;140:102432. [DOI:10.1016/j.ijhcs.2020.102432]

15. Afsharipour B, Sandhu MS, Rasool G, Suresh NL, Rymer WZ. Using surface electromyography to detect changes in innervation zones pattern after human cervical spinal cord injury. In2016 38th Annual International Conference of the IEEE Engineering in Medicine and Biology Society (EMBC) 2016 Aug 16 (pp. 3757-3760). IEEE. [DOI:10.1109/EMBC.2016.7591545] [PMID]

16. Choi C, Rim B, Kim J. Development and evaluation of a assistive computer interface by SEMG for individuals with spinal cord injuries. In2011 IEEE International Conference on Rehabilitation Robotics 2011 Jun 29 (pp. 1-5). IEEE.

17. Safavi SM, Sundaram SM, Heydarigorji A, Udaiwal NS, Chou PH. Application of infrared scanning of the neck muscles to control a cursor in human-computer interface. In 2017 39th Annual International Conference of the IEEE Engineering in Medicine and Biology Society (EMBC) 2017 Jul 11 (pp. 787-790). IEEE. [DOI:10.1109/EMBC.2017.8036942] [PMID]

18. Williams MR, Kirsch RF. Evaluation of head orientation and neck muscle EMG signals as command inputs to a human-computer interface for individuals with high tetraplegia. IEEE T NEUR SYS REH 2008 Sep

19;16(5):485-96.
[DOI:10.1109/TNSRE.2008.2006216] [PMCID]

19. Brooke J. Sus: a "quick and dirty'usability. Usability evaluation in industry. 1996 Jun 11;189.

20. Weller RO, Djuanda E, Yow HY, Carare RO. Lymphatic drainage of the brain and the pathophysiology of neurological disease. Acta Neuropathol. $2009 \quad$ Jan 1;117(1):1. [DOI:10.1007/s00401-008-0457-0] [PMID]

21. Sadoughi F, KHOSHKAM M, FARAHI SR. Usability evaluation of hospital information systems in hospitals affiliated with Mashhad University of Medical Sciences, Iran. 2012

22. 22. Dianat I, Ghanbari Z, AsghariJafarabadi M. Psychometric properties of the persian language version of the system usability scale. Health Promot Perspect. 2014;4(1):82. 